\title{
Molecular orientational properties of a high-tilt chiral smectic liquid crystal determined from its infrared dichroism
}

\author{
A. A. Sigarev, ${ }^{1, *}$ J. K. Vij,${ }^{1, \dagger}$ A. W. Hall, ${ }^{2}$ S. J. Cowling, ${ }^{2}$ and J. W. Goodby ${ }^{2}$ \\ ${ }^{1}$ Department of Electronic and Electrical Engineering, Trinity College, University of Dublin, Dublin 2, Ireland \\ ${ }^{2}$ Department of Chemistry, University of York, York, United Kingdom \\ (Received 29 March 2007; revised manuscript received 2 August 2007; published 29 November 2007)
}

\begin{abstract}
The orientational characterisitics and the temperature dependencies of the molecular apparent tilt angle of a partly fluorinated chiral smectic liquid crystal (/S/)-4-(1-methylheptyloxycarbonyl)phenyl 4' -[6-(3,4,4,4-tetrafluoro-3-trifluoromethylbutylcarbonyloxy)hexyloxy] biphenyl-4-carboxylate (acronym MHPHFHHOBC) are studied using the polarized Fourier transform infrared (FTIR) spectroscopy. The molecular orientational distributions and the orientational order parameters for a homogeneously aligned liquid crystalline sample at various temperatures and external electric fields are examined. The analysis uses the dichroic parameters of the phenyl and the carbonyl bands. For a temperature range of $65-80{ }^{\circ} \mathrm{C}$ corresponding to the antiferroelectric $\mathrm{Sm}_{A}{ }^{*}$ phase, the molecular apparent tilt angle lies within the range $43^{\circ}-44^{\circ}$; antiferroelectric smectic structure being rather close to the orthoconic $\mathrm{Sm}_{A}{ }^{*}$ phase. An application of sufficiently high dc field across the cell in its $\mathrm{Sm} A^{*}$ phase surprisingly shows that the dichroism first increases slowly and then rapidly in two stages and finally a saturated apparent tilt angle of $\sim 30^{\circ}$ is reached. The IR dichroic data is used to estimate the polar angles and the degree of rotational biasing of the carbonyl groups with respect to the molecular long axis. In the $\operatorname{Sm} A^{*}$ phase, the sample appears to demonstrate some of the typical properties of a de Vries material.
\end{abstract}

DOI: 10.1103/PhysRevE.76.051707

PACS number(s): 42.70.Df, 61.30.Gd, 77.80.-e, 78.30.-j

\section{INTRODUCTION}

An increasing interest in the antiferroelectric liquid crystals (AFLCs) with large molecular apparent tilt angles is related to their potential use in optical high-contrast transmission devices in displays and photonic devices by employing the surface-stabilized smectic- $C_{A}{ }^{*}\left(\mathrm{SmC}_{A}{ }^{*}\right)$ phase in the anticlinic state for the dark state and the field-induced $\mathrm{Sm} C^{*}$ as the bright state [1-10]. The compounds where the tilt angle in their $\mathrm{SmC}_{A}{ }^{*}$ phase is $45^{\circ}$ are called "orthoconic" AFLC materials since the smectic-tilt cone angle becomes $90^{\circ}$. For this case, an ideal surface-stabilized liquid crystalline cell in $\mathrm{SmC}_{A}{ }^{*}$ has its optical axis perpendicular to the windows of the cell in an unswitched state at zero field as the refractive index ellipsoid in the plane normal to this axis becomes a circle. In such a case, the transmittance through the cell between the crossed polarizers is zero, and furthermore it is almost independent of the quality of alignment of the liquid crystalline layer in the cell. The polarizer position is adjusted to make the field-induced smectic- $C^{*}\left(\mathrm{SmC} C^{*}\right)$ state as the bright state. This offers the advantage of a high quality, repeatable, and reliable performance of the planar cells between the "off" and "on" states. This is extremely important for the design of high-contrast LC devices that use this effect. Since the helical pitch of these materials is rather short and does not normally exceed $0.5 \mu \mathrm{m}$ at present, the cell thickness is restricted to be less than $1 \mu \mathrm{m}$ to obtaining a surface stabilized structure [1-9]. This condition puts considerably higher technological constraints on the manufacture of

\footnotetext{
*Permanent address: Research Institute of Physical Problems, 124460, Moscow, Russia.

${ }^{\dagger}$ Corresponding author; jvij@tcd.ie
}

cells with such lower cell spacings. The problem can be overcome by the synthesis of newer types of orthoconic AFLC materials or suitable mixtures with longer helical pitches such that the cells with larger cell thicknesses can be used. This poses significant new challenges to the synthetic chemists to synthesize AFLC compounds and their mixtures with a tilt angle of $45^{\circ}$ and with a macroscopic helical pitch of a few $\mu \mathrm{m}$.

The apparent tilt angle between the optic axis and the smectic layer normal of $\sim 45^{\circ}$ has been reported for AFLC compounds and their mixtures where the achiral tails are fluorinated [1-11] and in some cases where the core is also fluorinated [11]. The other method is to have the siloxane based monomers $[12,13]$ and dimeric compounds [14]. Recently several new de Vries ferroelectric multicomponent mixtures based on a new Ge-containing high-tilt AFLC material have been reported to have a tilt angle of $\sim 45^{\circ}$ over a rather wide temperature range of 20 to $90{ }^{\circ} \mathrm{C}$ [10]. The reason why the optical tilt angle in such AFLC materials is unusually high is not yet known exactly. It is reasonable to suggest that a combination of a large tilt of the fluorinated achiral chains and of the biasing of the tilt director fluctuations in LC compounds may possibly be the reasons for a large optical tilt in $\mathrm{SmC}_{A}{ }^{*}$ phase of such compounds. An extremely bent molecular configuration is also important in this consideration.

Some basic properties of de Vries $\mathrm{Sm} A^{*}$ of LC compounds with bent-shaped molecules containing bulky side molecular fragments have been studied using optical polarized microscopy, polarized infrared spectroscopy, and birefringence measurements [15-18]. The absorption anisotropy of the characteristic bands of the molecular fragments in a liquid crystalline molecule which is dependent on the relative orientation of their transition moments, biasing of the 
molecular rotational distributions and the molecular alignment can yield useful information about the molecular arrangement in a liquid crystalline phase. Dependencies of the orientational order parameter of the biphenyl C-C stretching vibrations, for which the transition moments make rather small polar angles with the molecular long axis, on temperature and the electric field applied across the sample, yield information about the extent of the order in a phase. The molecular long axis is defined as the axis about which the moment of inertia is minimum. The orientational distribution functions of the molecular fragments, especially those of the carbonyl group attached close to the chiral carbon, may yield information about the polar order as well as the quadrupolar ordering [19-29] of the short axes. The average molecular tilt angle found using IR anisotropy in principle can be different from that found using x-ray scattering and the optical microscopic methods since different methods probe different physical entities.

In this paper polarized Fourier transform infrared (FTIR) spectroscopy is used to study the orientational behavior of a liquid crystal compound that exhibits two interesting structural properties: (i) a rather large molecular optical apparent tilt angle $\left(\sim 44^{\circ}\right)$ in its $\mathrm{SmC}_{A}{ }^{*}$ phase and (ii) a comparatively large molecular optical apparent tilt angle $\left(\sim 30^{\circ}\right)$ for the field-induced synclinic structure in the temperature range corresponding to $\operatorname{Sm} A^{*}$ at zero field. The results on the thickness measurements obtained using X-ray diffraction given in Sec. II suggest this material to be partially de Vries with the molecules tilted with a narrow distribution of tilt angle in $\mathrm{Sm} A^{*}$ with respect to the smectic layer normal but the molecules azimuthally randomly distributed. The spatial length within which the azimuthal directions are correlated lies in the subvisible region.

The orientational distributions of the molecular director and of some polar groups are determined from the analysis of the dichroic parameters of several characteristic IR absorption bands in a homogeneously aligned LC sample at various temperatures and external electric fields. The homogeneity and the phase state of the LC sample are examined using polarized optical microscopy. The temperature dependence of the average molecular apparent tilt angle is determined from the voltage dependent anisotropy of the highdichroic phenyl vibrational bands. The dichroic data for the phenyl and the carbonyl bands for the field-induced synclinic structures are used to determine some parameters of the biasing in the rotational orientational distributions of the carbonyl and the phenyl groups with respect to the molecular long axes for the various smectic phases. The role of the molecular structure on the biasing of the rotational distributions, and on the orientational order parameter and on the large optical tilt angle, is discussed.

\section{EXPERIMENT}

A chiral smectic liquid crystal

$$
\begin{aligned}
& (/ S /)-4-\left(1-\text { methylheptyloxycarbonylphenyl }-4^{\prime}-\right. \\
& [6-(3,4,4,4-\text { tetrafluoromethylbutylcarbonyloxy }) \text { hexyloxy })] \text { biphenyl }-4-\text { carboxylate }
\end{aligned}
$$

(acronym MHPHFHHOBC, lab name AH43) with a partly fluorinated achiral tail is studied. The structural formula of the compound is shown in Fig. 1(a). The phase sequences under cooling obtained using differential scanning calorimetry (DSC) in the bulk of the compound: Iso. $129.3{ }^{\circ} \mathrm{C}$ $\mathrm{Sm}^{*}{ }^{*} 123.5^{\circ} \mathrm{C} \mathrm{SmC}^{*} 116.3{ }^{\circ} \mathrm{C} \mathrm{SmC}_{A}{ }^{*} 57.7^{\circ} \mathrm{C}$ Cryst.; and Iso. $125.3{ }^{\circ} \mathrm{C} \mathrm{Sm} A^{*} 120.2{ }^{\circ} \mathrm{C} \quad \mathrm{Sm}^{*} 115^{\circ} \mathrm{C} \mathrm{SmC}_{A}{ }^{*}$ $57.5^{\circ} \mathrm{C}$ Cryst. using polarized optical microscopy and IR spectroscopy for a homogeneousely aligned sample of the compound in a cell of $6 \mu \mathrm{m}$ thickness. For a thin layer of this compound, the temperatures of the phase transitions are found to be $\sim 3$ to $4{ }^{\circ} \mathrm{C}$ lower than for the bulk determined using DSC. $\operatorname{Sm} A^{*}$ to $\operatorname{Sm} C^{*}$ transition is found to be first order using DSC with an enthalpy of $1.201 \mathrm{~kJ} \mathrm{~mol}^{-1}$. The studied material in its unwound $\mathrm{SmC}^{*}$ structure is found to exhibit a rather large spontaneous polarization $P_{\mathrm{S}}$ $=180 \mathrm{nC} / \mathrm{cm}^{2}$.

Figure 2 shows the results on the smectic layer thickness of the compound obtained using x-ray diffraction technique. The layer thickness in the material is found to be almost constant over the temperature range of $\mathrm{SmC}_{A}{ }^{*}$, whereas over the temperature range of the $\operatorname{Sm} A^{*}$ and $\mathrm{Sm}^{*}$ phases the relative change in the thickness is less than $6 \%$, including a $\sim 2 \%$ change at $123.5^{\circ} \mathrm{C}$, corresponding to the phase transition $\mathrm{Sm} A^{*}-\mathrm{Sm} C^{*}$. This change is substantially less than relative changes of $\sim 30 \%$ and $13 \%$ that could be expected

(a)

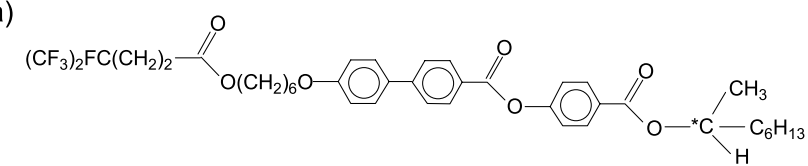

(b)

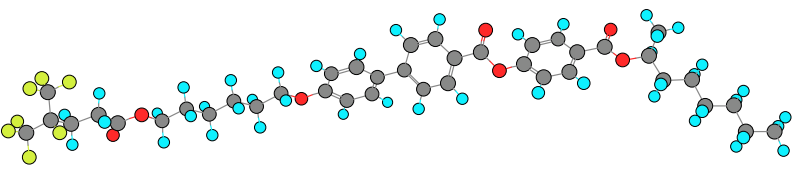

FIG. 1. (Color online) The structural formula of MHPHFHHOBC (a). The phase sequences under cooling obtained using DSC in the bulk of the compound: Iso. $129.3^{\circ} \mathrm{C} \mathrm{SmA}^{*} 123.5^{\circ} \mathrm{C} \mathrm{SmC}{ }^{*}$ $116.3{ }^{\circ} \mathrm{C} \mathrm{SmC}_{\mathrm{A}}{ }^{*} 57.7^{\circ} \mathrm{C}$ Cryst.; and Iso. $125.3{ }^{\circ} \mathrm{C} \mathrm{SmA}{ }^{*}$ $120.2{ }^{\circ} \mathrm{C} \mathrm{SmC}{ }^{*} 115{ }^{\circ} \mathrm{C} \mathrm{SmC}_{\mathrm{A}}{ }^{*} 57.5^{\circ} \mathrm{C}$ crystal, by using polarized optical microscopy and IR spectroscopy for a homogeneousely aligned sample of the compound in a cell of $6 \mu \mathrm{m}$ thickness. The ball and stick structural model obtained for its single molecule using MOPAC procedure (b). 


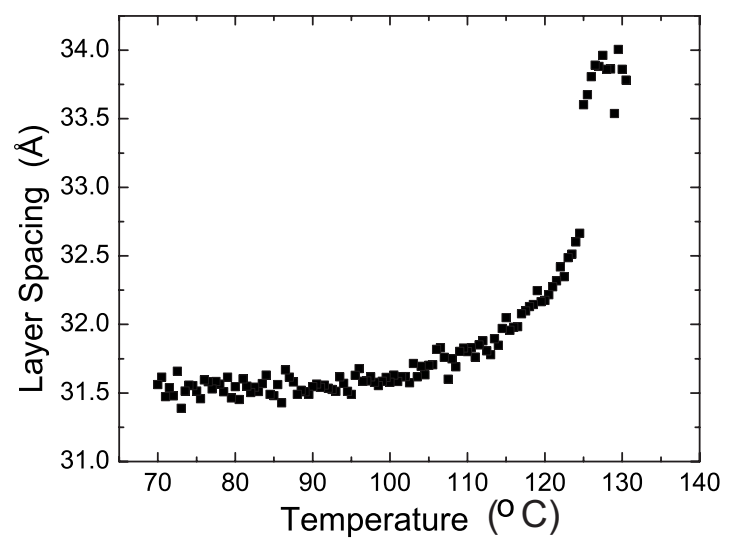

FIG. 2. The temperature dependence of the layer spacing of MHPHFHHOBC using x-ray scattering.

for tilt angles of $45^{\circ}$ and $30^{\circ}$ if the molecule is assumed to be a rigid rod of a fixed length in $\operatorname{Sm} A^{*}$ phase. This may suggest that the material is at least partially de Vries, where the in-layers directors are tilted in the $\operatorname{Sm} A^{*}$ phase with a narrow distribution of tilt angle with a certain azimuthal angle within a correlation length of several $\mathrm{nm}$ but the molecules within the same narrow tilt angle distribution are azimuthally randomly distributed away from it. In a perfect de Vries material, the typical layer shrinkage is of the order of $1 \%$ [30].

Optical measurements were carried out using a planar sandwich-type LC cell consisting of two optically polished $\mathrm{CaF}_{2}$ substrates mounted at a gap of $2 \mu \mathrm{m}$ thickness. The cell was filled with a LC material in its isotropic phase. Each substrate of $2 \mathrm{~mm}$ thickness and dimensions of $25 \times 12 \mathrm{~mm}$ coated initially with a thin layer of indium tin oxide (ITO) was spin coated with a thin aligning layer of Nylon 6,6. One of the two substrates was rubbed in a direction parallel to the long side of the substrate so as to be sure of the direction of rubbing. Rubbing of only one substrate gives a better uniformity in the alignment of the LC layer than when both substrates are rubbed due to the surface electroclinic effect. The cell gap thickness was set using Mylar film stripes. The LC sample was homogeneousely aligned on the substrates during slow cooling from the isotropic phase. Figure 3 shows the orientations of the rubbing direction (vector $\mathbf{R}$ ), the smectic layer normal (vector $\mathbf{K}$ ), and the electric vector of polarized IR radiation $\left(\mathbf{E}_{\mathrm{IR}}\right)$ in the coordinate system $\left(X_{C}, Y_{C}, Z_{C}\right)$ fixed to the LC cell. A hot stage in to which a LC cell was inserted was mounted in a sample compartment of the spectrometer. The laboratory coordinate system related to the spectrometer was chosen to coincide with the frame $\left(X_{C}, Y_{C}, Z_{C}\right)$. The second coordinate system $(X, Y, Z)$ shown in Fig. 3 is introduced to take into account the finite angular shift (angle $\vartheta \approx 12^{\circ}$ ) of the smectic layer normal with respect to the rubbing direction of the substrate for the reasons that will be obvious later.

The polarized spectra in the wave number $(\nu)$ range $1000-4000 \mathrm{~cm}^{-1}$ were measured using a Bio-Rad (Digilab) FTS-6000A spectrometer with a Mercury Cadmium Telluride (MCT) detector, a wire-grid polarizer, and a hot stage for the LC cell. A controlled temperature stability within $\pm 0.1^{\circ} \mathrm{C}$ for the cell over a wide range of temperatures was achieved.

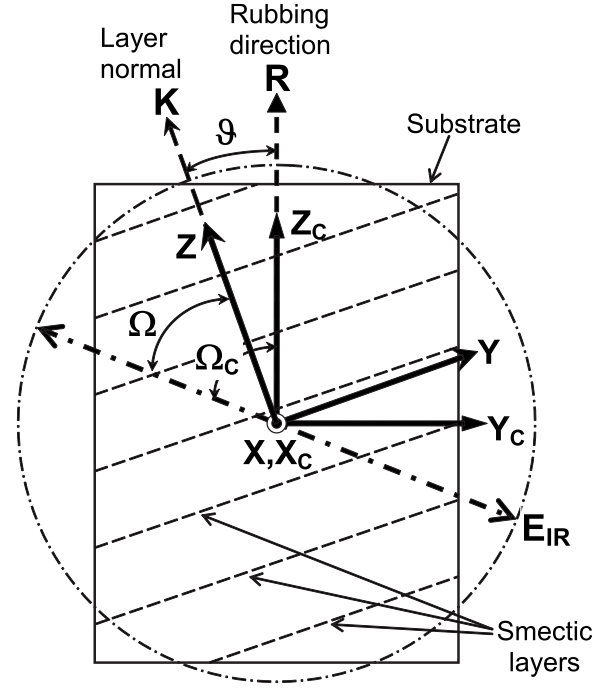

FIG. 3. A schematic illustration of the orientations of the smectic layer normal and the IR radiation polarization direction with respect to the rubbing direction for a cell substrate. The frame $\left(X_{C}, Y_{C}, Z_{C}\right)$ is related to the LC cell: $X_{\mathrm{C}}$ axis is normal to the cell substrates and lies along the IR propagation direction and the electric field, $Z_{\mathrm{C}}$ axis is parallel to the rubbing direction (vector $\mathbf{R}$ ). The frame $(X, Y, Z)$ is related to the smectic layers: $X$ axis is parallel to $X_{\mathrm{C}}$ axis, the $Z$ axis is parallel to the smectic layer normal (vector $\mathbf{K}$ ) found from the IR dichroic data in $\mathrm{SmA}^{*} . \Omega_{C}$ and $\Omega$ are the angles between the electric vector $\mathbf{E}_{\mathrm{IR}}$ of polarized IR radiation and the axes $Z_{\mathrm{C}}$ and $Z$, respectively.

A transmission method at the normal incidence of IR radiation to the cell substrates was used. A signal-to-noise ratio $S / N>2000$ was obtained after averaging of 16 scans for a spectral resolution $2 \mathrm{~cm}^{-1}$. Spectra were recorded for various temperatures corresponding to the $\operatorname{Sm} A^{*}, \mathrm{Sm}^{*}$, and $\mathrm{Sm}_{A}{ }^{*}$ phases of the sample. The orientation of the smectic layer normal (vector $\mathbf{K}$ in Fig. 3) with respect to the rubbing direction (vector $\mathbf{R}$ ) was characterized by a finite angle $\Omega_{C(\vartheta)}$ $=\vartheta \approx 12^{\circ}$ corresponding to the maximal absorbance for the high dichroic phenyl absorption band at $1525 \mathrm{~cm}^{-1}$ for the sample in $\operatorname{Sm} A^{*}$ phase for the temperature range of 120.5-122.5 ${ }^{\circ} \mathrm{C}$ and zero external field. The respective polarization angle $\Omega$ described in the captions to Figs. 3 and 4 was determined from the equation $\Omega=\Omega_{C}-\vartheta$.

Spectra were recorded as a function of the dc bias voltages $\left(U_{\mathrm{DC}}\right)$ applied across the cell from zero to sufficiently large (of both polarities) so to totally unwind the helical structure at a given temperature. For each bias voltage, the absorption spectra were recorded for a set of the polarizer rotation angles $\Omega_{C}$ in the range $0^{\circ}-180^{\circ}$ in steps of $10^{\circ}$. The angular step $\Delta \Omega_{C}$ of $6^{\circ}$ was also used for some spectral measurements to obtain a higher accuracy in the determination of the dichroic parameters of bands. In order to determine the peak positions, intensities, and the widths of the absorption bands, standard peak-fitting software programs GRAMS and ORIGIN 7.5 were used. The studied absorption bands of the material are listed in Table I. 
TABLE I. Assignments for several absorption bands in the IR spectrum of MHPHFHHOBC in accordance with Refs. [32,34,44].

\begin{tabular}{|c|c|c|c|}
\hline $\begin{array}{l}\text { Band } \\
\left(\mathrm{cm}^{-1}\right)\end{array}$ & Groups & Type of vibrations & $\begin{array}{l}\text { Relative } \\
\text { dichroism }\end{array}$ \\
\hline 1525 & $\begin{array}{l}\text { Aromatic rings } \mathrm{C}_{6} \mathrm{H}_{4} \text { for the phenyl } \\
\text { and biphenyl fragments }\end{array}$ & $\begin{array}{l}\text { C-C stretchings combined } \\
\text { with } \mathrm{C}-\mathrm{C}-\mathrm{H} \text { deformations }\end{array}$ & high \\
\hline 1603 & $\begin{array}{l}\text { Aromatic rings } \mathrm{C}_{6} \mathrm{H}_{4} \text { for the phenyl } \\
\text { and biphenyl fragments }\end{array}$ & $\begin{array}{l}\mathrm{C}-\mathrm{C} \text { stretchings combined } \\
\text { with } \mathrm{C}-\mathrm{C}-\mathrm{H} \text { deformations }\end{array}$ & high \\
\hline 1715 & $\mathrm{C}=\mathrm{O}$ (near the chiral center) & stretchings & low \\
\hline 1741 & $\begin{array}{l}\mathrm{C}=\mathrm{O} \text { (in the core part) } \\
\mathrm{C}=\mathrm{O} \text { (in the achiral tail) } \\
\text { (two overlapping bands) }\end{array}$ & $\begin{array}{l}\text { stretchings } \\
\text { stretchings }\end{array}$ & very low \\
\hline 2862 & $\mathrm{CH}_{2}$ & symmetric stretchings & very low \\
\hline 2937 & $\mathrm{CH}_{2}$ & asymmetric stretchings & very low \\
\hline
\end{tabular}

\section{THEORETICAL CONSIDERATION}

\section{A. Molecular structure}

The ball-and-stick model of the molecular structure of the compound obtained using the energy minimization technique Molecular Orbital Package (MOPAC) is shown in Fig. 1(b). This conformation corresponds to a single molecule in the absence of any intermolecular interactions. The shape of the molecule is rather bent. The axes of the terminal chiral and achiral tails make polar angles of $\sim 65^{\circ}$ and $\sim 25^{\circ}$ with the average core axis. The latter refers to the average axis of the core containing the biphenyl and the phenyl rings. The central core is bent due to the ester linkage in between the biphenyl and the phenyl segments of the molecule. The paraaxes of the phenyl and the biphenyl fragments are not parallel to each other: the angle between these two axes is $\sim 15^{\circ}$. Both of these para-axes make angles of the order of $10^{\circ}-20^{\circ}$ with the molecular long axis. For the biphenyl, there is an angle of $\sim 30^{\circ}$ between the aromatic rings. The plane of the phenyl fragment is twisted by $\sim 60^{\circ}$ with respect to the nearest aromatic ring of the biphenyl fragment.

It is important to note that this model is only an approximation to the real molecular structure in a liquid crystalline phase. The twisting of the biphenyl fragment in a chiral liquid crystalline compound was found to decrease with a reduction in temperature using Raman spectroscopy [33]. However, the structure of the solid crystalline biphenyl in general is known to be planar [20,33]. Presumably a more planar (less twisted) structure of the biphenyl fragment of the entire aromatic core part of a molecule is more favorable for the interaction of $\pi$ electrons of the aromatic rings in the neighboring molecules in a LC phase. The intermolecular interactions for the LC state are strong enough to influence the structural and the phase behavior of the materials.

An important molecular structural property of the compound MHPHFHHOBC is the presence of a terminal fragment $\mathrm{CF}\left(\mathrm{CF}_{3}\right)_{2}$ and an ester linkage in the achiral tail. Seven heavy fluorine atoms at the end of the achiral tail significantly influence the position of the mass center and the orientation of the long molecular axis in a molecule, and these in turn influence the polar angles $\beta$ of the transition moments of the IR active vibrations. In comparison to a nonfluorinated molecule, the mass center is slightly shifted towards the achiral tail, the polar angles for the axes of the achiral tail, and the core part with respect to the molecular long axis are expected to be lower and higher by several degrees, respectively. The transition moments of both phenyl bands at 1603 and $1525 \mathrm{~cm}^{-1}$ (corresponding to a combination of the localized $\mathrm{C}-\mathrm{C}$ stretching vibrations and the $\mathrm{C}-\mathrm{C}-\mathrm{H}$ deformations), make relatively small angles with the para-axis of a respective phenyl rings [34]. In general, for each phenyl band the respective transition moments for the phenyl and biphenyl fragments should be considered separately with different angles with respect to the molecular long axis. However, since the phenyl and biphenyl para-axes make a sufficiently small angle $\left(\leqslant 15^{\circ}\right)$ with each other, we only consider some effective polar angles of $\beta_{1603}$, and $\beta_{1525}$ for these two bands as approximation. The transition moment of the $\mathrm{C}=\mathrm{O}$ stretching vibrations makes an angle less than $20^{\circ}$ with the carbonyl bond [34,35]. In Sec. IV, the polar angles $\beta_{1715}$, $\beta_{1603}$, and $\beta_{1525}$ are determined from the experimental dichroic data for the compound investigated here.

\section{B. Absorbance parameters}

Figure 4 illustrates the orientations of the molecular axes and the vibrational transition moments in the coordinate frame $(X, Y, Z)$ with the smectic layer normal fixed as the $Z$ axis in terms of the angles $\Theta, \varphi, \beta$, and $\gamma$ defined in the figure caption. The expressions for the components of the transition moment $\mathbf{M}: M_{X}, M_{Y}, M_{Z}$ in terms of angles $\Theta, \varphi$, $\beta$, and $\gamma$ are given by Eqs. (2)-(4) in Ref. [27]. For the IR radiation incident normally to the windows of a LC cell along the $X$ axis (see Figs. 2 and 4), the absorbance anisotropy of the sample for a vibrational band with the maximum at a wave number $\nu$ can be characterized by the absorbances $A_{Y}, A_{Z}$, and $A_{Y Z}$ in the frame $(X, Y, Z)$ related to the cell substrates and the smectic layer normal. These are expressed in terms of $M_{X}, M_{Y}, M_{Z}$ as the components along $X, Y$, and $Z$ axes, respectively; $k$ is a constant coefficient. 


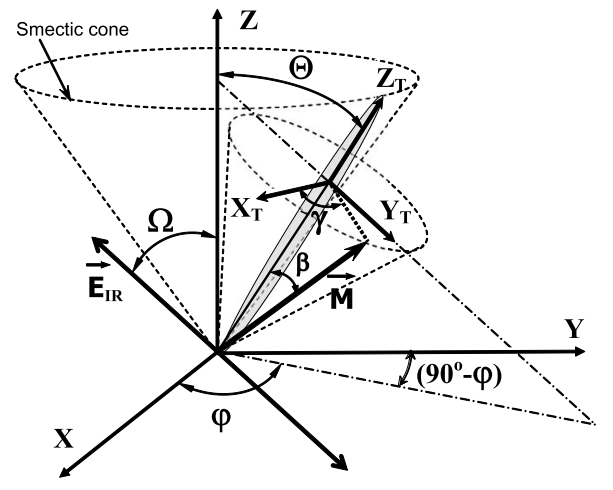

FIG. 4. A schematic representation of the molecular orientations, transition moments, and the IR radiation polarization direction in the frame $(X, Y, Z)$ related to the smectic layers in a LC cell: $X$ axis is normal to the cell substrates and is along the IR radiation propagation direction and the electric field direction, $Z$ axis is parallel to the smectic layer normal, $\Omega$ is the angle between the electric vector $\mathbf{E}_{\mathrm{IR}}$ of polarized IR radiation at normal incidence and $Z$ axis. The frame $\left(X_{\mathrm{T}}, Y_{T}, Z_{\mathrm{T}}\right)$ is related to the molecular tilt plane: $Z_{\mathrm{T}}$ axis is parallel to the molecular long axis and makes the polar angle $\Theta$ with the $Z$ axis and the azimuthal angle $\varphi$ with the $X$ axis, $X_{\mathrm{T}}$ is normal to the tilt plane. The transition moment $\mathbf{M}$ of a certain vibration is described by the polar angle $\beta$ with respect to the molecular long axis and the azimuthal angle $\gamma$ measured from $X_{\mathrm{T}}$.

$$
\begin{gathered}
A_{Y}=k\left\langle M_{Y}{ }^{2}\right\rangle /|\mathbf{M}|^{2}, \quad A_{Z}=k\left\langle M_{Z}{ }^{2}\right\rangle /|\mathbf{M}|^{2}, \\
A_{Y Z}=k\left\langle M_{Y} M_{Z}\right\rangle /|\mathbf{M}|^{2} .
\end{gathered}
$$

Averaging in Eq. (1) is carried out over all possible orientations of the individual transition moments for all molecules in the LC sample. The polar angles $\beta_{1525}, \beta_{1603}$, and $\beta_{1715}$ for the phenyl and carbonyl bands at 1525,1603 , and $1715 \mathrm{~cm}^{-1}$, respectively, are assumed to be constant for all the molecules. For an arbitrary molecular azimuthal distribution of the in-layer director through the angle $\varphi$, the equations for $A_{Y}, A_{Z}$, and $A_{Y Z}$ in terms of the functions of $\Theta, \varphi, \beta$, and $\gamma$ are given in [29]. For the case of an unwound synclinic structure with the azimuthal angle $\varphi=90^{\circ}$ for all the molecules, the following equations for the absorbances can be written $[23,27]$ :

$$
\begin{aligned}
A_{Y}= & k\left\{\cos ^{2} \beta\left\langle\sin ^{2} \Theta\right\rangle+\sin ^{2} \beta\left\langle\cos ^{2} \Theta\right\rangle\left\langle\sin ^{2} \gamma\right\rangle\right. \\
& +2 \sin \beta \cos \beta\langle\sin \Theta \cos \Theta\rangle\langle\sin \gamma\rangle\}, \\
A_{Z}= & k\left\{\cos ^{2} \beta\left\langle\cos ^{2} \Theta\right\rangle+\sin ^{2} \beta\left\langle\sin ^{2} \Theta\right\rangle\left\langle\sin ^{2} \gamma\right\rangle\right. \\
& -2 \sin \beta \cos \beta\langle\sin \Theta \cos \Theta\rangle\langle\sin \gamma\rangle\}, \\
A_{Y Z}= & k\left\{\left(\cos ^{2} \beta-\sin ^{2} \beta\left\langle\sin ^{2} \gamma\right\rangle\right)\langle\sin \Theta \cos \Theta\rangle\right. \\
& \left.+\sin \beta \cos \beta\langle\sin \gamma\rangle\left(\left\langle\cos ^{2} \Theta\right\rangle-\left\langle\sin ^{2} \Theta\right\rangle\right)\right\} .
\end{aligned}
$$

The molecular orientational distributions in the tilt plane are described by the averaged functions $\left\langle\cos ^{2} \Theta\right\rangle$ and $\langle\sin \Theta \cos \Theta\rangle$ used in Eqs. (2)-(4). The mode corresponding to the director fluctuations in $\Theta$ in the tilt plane is termed as the soft mode. The averages $\langle\sin \gamma\rangle$ and $\left\langle\sin ^{2} \gamma\right\rangle$ characterize the rotational orientational distributions of the transition mo- ments of a band in the molecular frame $\left(X_{\mathrm{T}}, Y_{\mathrm{T}}, Z_{\mathrm{T}}\right)$ through the azimuthal angle $\gamma$ measured with respect to the tilt plane normal ( $X_{\mathrm{T}}$ axis shown in Fig. 4). In the case of an unwound structure, $X_{\mathrm{T}}$ coincides with axes $X$ and $X_{\mathrm{C}}$ and is normal to the cell substrates for all molecules of a LC sample.

For the observed angular dependence of the peak intensity of a certain band, $A(\Omega)$, as a function of the angle of polarization $\Omega$ (called the absorbance profile), the maximal $\left(A_{\max }\right)$ and minimal $\left(A_{\min }\right)$ absorbances correspond to the IR radiation polarization angles of $\Omega_{\max }$ and $\left(\Omega_{\max }+90^{\circ}\right)$, respectively. These parameters are found by fitting the function $[23,36]$

$$
\begin{aligned}
A(\Omega)= & -\log _{10}\left[10^{-A_{\max }} \cos ^{2}\left(\Omega-\Omega_{\max }\right)\right. \\
& \left.+10^{-A_{\min }} \sin ^{2}\left(\Omega-\Omega_{\max }\right)\right]
\end{aligned}
$$

to the experimental data. The accuracy of determining of $A_{\max }, A_{\min }$, and $\Omega_{\max }$ for the experimental absorbance profiles using this function is briefly discussed in Sec. IV. In principle we can determine these parameters with higher accuracy by recording the absorbance of bands for a discrete number of the polarization angles $\Omega_{C(i)}$ chosen with a small angular step $\Delta \Omega_{C}$. Note that the coefficient $k$ used in Eqs. (1)-(4) is unknown and can be different for different bands due to the anisotropic and dispersive properties of the material, especially when a comparison is made for different temperatures. To eliminate $k$ for Eqs. (1)-(4), for each band we consider two independent dichroic ratios $R_{Y, Z}$ and $R_{Y Z, Z}$ defined by the absorbances $A_{Y}, A_{Z}$, and $A_{Y Z}$ by the equations $[27,29]$

$$
\begin{gathered}
R_{Y, Z}=A_{Y} / A_{Z}, \\
R_{Y Z, Z}=A_{Y Z} / A_{Z} .
\end{gathered}
$$

By using Eqs. (2)-(4), the ratios $R_{Y, Z}$ and $R_{Y Z, Z}$ are expressed as functions of angles $\Theta, \varphi, \beta_{\nu}$, and $\gamma_{\nu}$. The numerical values of the dichroic ratios $R_{Y, Z}$ and $R_{Y Z, Z}$ can be found in terms of the fitted parameters $A_{\max }, A_{\min \nu}$, and $\Omega_{\max \nu}$ of the experimental absorbance profile for a band using the equations $[23,27]$

$$
\begin{aligned}
& A_{Y}=A_{\min } \cos ^{2} \Omega_{\text {max }}+A_{\max } \sin ^{2} \Omega_{\text {max }}, \\
& A_{Z}=A_{\min } \sin ^{2} \Omega_{\text {max }}+A_{\text {max }} \cos ^{2} \Omega_{\text {max }}, \\
& A_{Y Z}=\left(A_{\min }-A_{\max }\right) \sin \Omega_{\max } \cos \Omega_{\max } .
\end{aligned}
$$

These are then used to determine $\langle\sin \gamma\rangle$ and $\left\langle\sin ^{2} \gamma\right\rangle$ as shown in Sec. IV.

\section{RESULTS AND DISCUSSION}

\section{A. Experimental absorbance profiles}

The polarized IR absorption spectra of the compound in the cell are illustrated by the examples shown in Fig. 5. The most important bands of the compound lie in the wave number range $1400-3200 \mathrm{~cm}^{-1}$. Their assignments and relative dichroic ratios are listed in Table I. The well resolved bands 

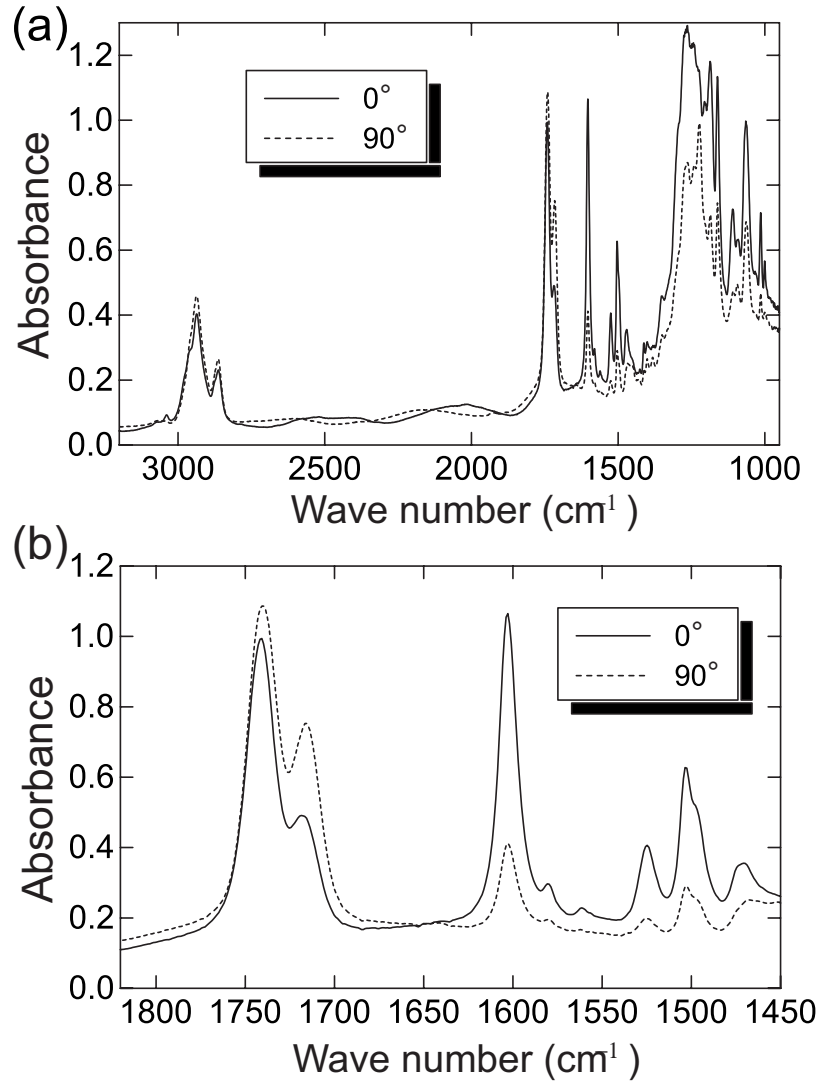

FIG. 5. The polarized IR spectra in $\mathrm{SmA}^{*}$ at a temperature of $122{ }^{\circ} \mathrm{C}$ for zero field for the IR radiation polarized parallel to the smectic layer normal (solid curve for $\Omega=0^{\circ}$ ) and perpendicular to it (dashed curve for $\Omega=90^{\circ}$ ). Spectral ranges: (a) 3200-950 $\mathrm{cm}^{-1}$; (b) $1820-1450 \mathrm{~cm}^{-1}$. Ordinate in above figure in $\mathrm{cm}^{-1}$.

at 1525 and $1603 \mathrm{~cm}^{-1}$ for the stretching vibrations of the phenyl groups and the band at $1715 \mathrm{~cm}^{-1}$ for the carbonyl group near the chiral center are used for the analysis. A lowdichroic peak with a maximum at $1741 \mathrm{~cm}^{-1}$ is found to be a superposition of the two strongly overlapping bands related to the stretching vibrations of the carbonyl groups situated in the core and in the achiral tail of molecules. The IR absorption spectrum of a solid polycrystalline powder of the compound in $\mathrm{KBr}$ matrix pressed into a tablet showed a complex structure for this band at $1741 \mathrm{~cm}^{-1}$. For this reason, this band is not used in the analysis, since the polar and azimuthal angles $\beta$ and $\gamma$ are different for the transition moments of these two types of $\mathrm{C}=\mathrm{O}$ groups. The bands of $\mathrm{C}-\mathrm{F}$ stretching vibrations in the range $1200-1400 \mathrm{~cm}^{-1}$ overlap with the skeleton vibrational bands of the aliphatic chains and these can also not be directly used for a quantitative analysis of the results either.

The IR radiation polarization direction that corresponds to the maximal absorbance for the intense phenyl band at $\nu$ $\approx 1600 \mathrm{~cm}^{-1}$ is usually used for characterizing the preferable orientation of the molecular directors (the molecular long axes) in aligned LC samples; as a first approximation, the polar angle $\beta_{1600}$ of this vibration is assumed to be zero $[22,23,25-29,31]$. In order to determine the molecular orientational distribution function accurately, it is necessary to take possible finite values of $\beta_{1600}$ into account. For various AFLC compounds, the values of $\beta_{1600}$ lies in the range from $12^{\circ}[27,31]$ to $25^{\circ}[25]$. For the studied material here, $\beta_{1603}$ is also not less than $12^{\circ}$ (as discussed below).

The experimental data at zero field for the highly dichroic bands of 1525 and $1603 \mathrm{~cm}^{-1}$ analyzed using the fitting function (5) for the temperature range of $120.5-122.5^{\circ} \mathrm{C}$ corresponding to $\operatorname{Sm} A^{*}$ (Fig. 6), shows that the maximal intensities for these bands are observed for the polarization angles $\Omega_{C \max 1603}$ and $\Omega_{C \max 1525}$ of about $12^{\circ}$ in the laboratory frame $\left(X_{\mathrm{C}}, Y_{\mathrm{C}}, Z_{\mathrm{C}}\right)$ described in Fig. 2. This result proves the existence of a finite deviation angle $\vartheta \approx 12^{\circ}$ made by the smectic layer normal with the rubbing direction for the investigated LC cell (see Fig. 3). This large deviation angle $\vartheta$ is attributed to the surface electroclinic effect [37-39]. Such a large value of $\vartheta$ presumably distorts the helical structure of the compound at zero voltage. The extremely large surface electroclinic effect with a deviation angle of $\vartheta \approx 20^{\circ}$ was reported earlier for a partly fluorinated compound [40] and an anomalously large surface electroclinic effect has been observed for the Tokyo mixture that gave rise to a thresholdless V-shape switching. For the compounds of the Tokyo mixture the deviation angles were found to be $\sim 12^{\circ}$ and $\sim 20^{\circ}$ for the cells with the polyimide and the nylon aligning layers, respectively [41]. Such a large surface-induced deviation angle will give rise to polar ordering in the $\operatorname{Sm} A^{*}$ phase with a finite surface-induced polarization. This effect has already been proven to exist and has experimentally been observed for a LC compound using the pyroelectric technique [42].

For the compound, the polarizer rotation angle with respect to the frame $(X, Y, Z), \Omega$, can be found using the relation: $\Omega=\Omega_{C}-\vartheta$ (see Fig. 3). The results for absorbance profiles $A(\Omega)$ for the two phenyl bands at 1525 and $1603 \mathrm{~cm}^{-1}$ and for the carbonyl band at $1715 \mathrm{~cm}^{-1}$ were obtained for zero field and for electric fields of both polarities that exceed the saturating fields for unwinding the electric-field-induced $\mathrm{SmC} C^{*}$ structure for various temperatures corresponding to the $\mathrm{Sm} A^{*}, \mathrm{SmC}^{*}$, and $\mathrm{SmC}_{A}{ }^{*}$ phases. A summary of the results for the most intense band at $1603 \mathrm{~cm}^{-1}$ is shown in Fig. 6 as polar plots. The dichroic parameters for zero and saturating fields for several temperatures on a few important bands are given in Table II. The maximal dichroism was observed for the phenyl band at $1525 \mathrm{~cm}^{-1}$. The dichroic ratio $R_{1525}=A_{\max } 1525 / A_{\min 1525}$ was found to be up to 13.5 for the field-induced ferroelectric structures. Somewhat less dichroism with a maximum of 10.2 was observed for the phenyl band at $1603 \mathrm{~cm}^{-1}$. For the carbonyl band at $1715 \mathrm{~cm}^{-1}$, a comparatively low dichroism was observed $\left(R_{1715}\right.$ lie within the range from 2 to 3 ). It is known that differences in the relative dichroic ratios for the various absorption bands are dependent not only on the molecular arrangement in the aligned sample, but also on the polar angles between the respective transition moments and the molecular axes $[22,23,26,27,34]$. The dichroic ratio $R=A_{\max } / A_{\min }$ for an ideal unwound synclinic structure with free rotational orientational distribution of the transition moments through the azimuthal angle $\gamma$ can be estimated using the formula $R$ $=2 \cot ^{2} \beta$ [27,29]. So the relation $R_{1525}\left(U_{1}\right)>R_{1603}\left(U_{1}\right)$ gives an estimation $\beta_{1525}<\beta_{1603}$. 

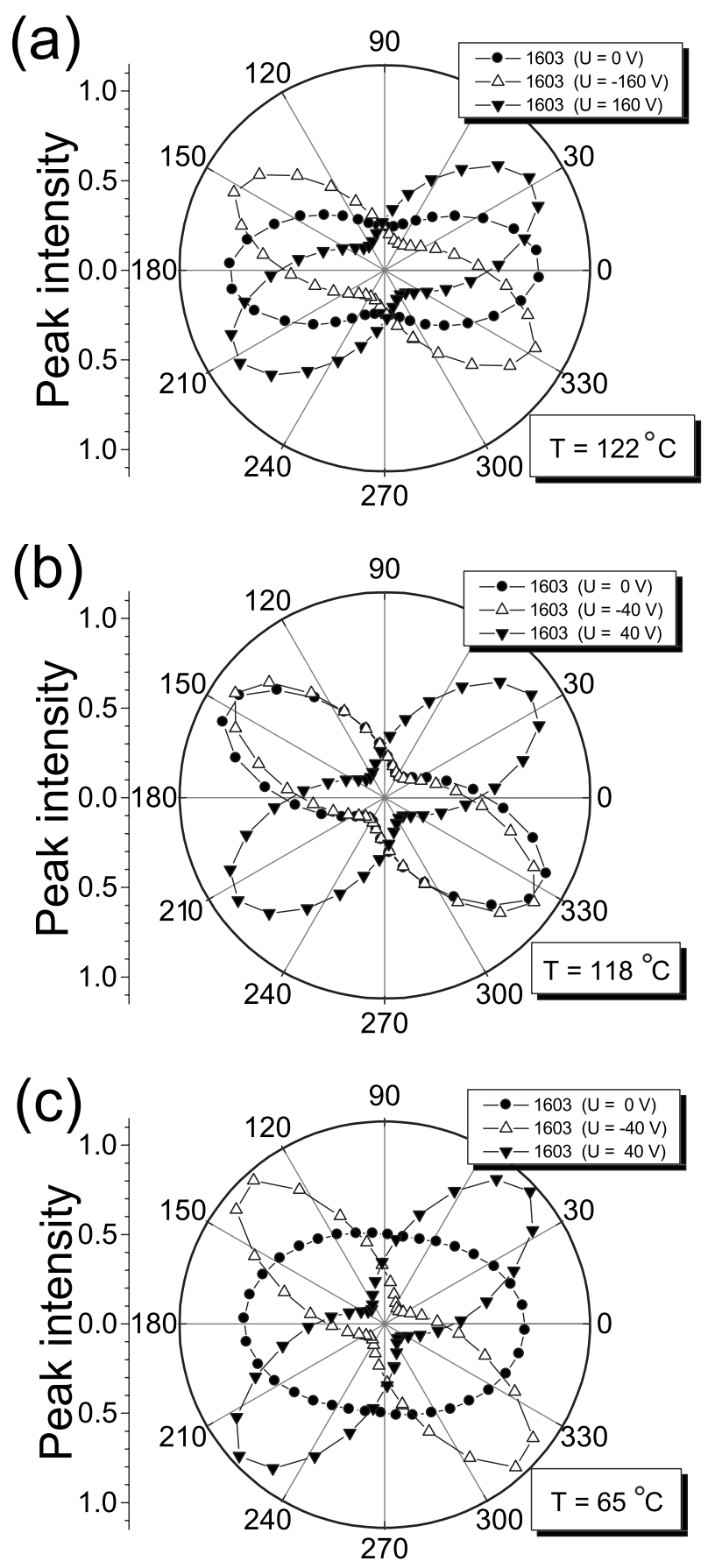

FIG. 6. Polar plots of the absorbance profiles $A(\Omega)$ for the phenyl band at $1603 \mathrm{~cm}^{-1}$ for zero field $(\boldsymbol{O})$ and the positive $(\boldsymbol{\nabla})$ and negative $(\triangle)$ saturating fields for the studied homogeneously aligned cell of 6 ( $\mathrm{m}$ thickness at temperatures $122{ }^{\circ} \mathrm{C}(\mathrm{a}), 118{ }^{\circ} \mathrm{C}$ (b), and $65^{\circ} \mathrm{C}$ (c). Values of applied voltages are shown in the inset. Lines interconnect the adjacent experimental points.

It has been found that the function (5) fits the experimental data for the high-dichroic phenyl band with different accuracies in the regions of the minimums and maximums of the absorbance profiles for opposite polarities of the saturating electric fields. For the low dichroic band at $1715 \mathrm{~cm}^{-1}$, experimental data are fitted extremely well with Eq. (5). This will be discussed in a separate publication. As seen from Fig.
7, for $U_{\mathrm{DC}}=40 \mathrm{~V}$, the maximal positive values of $\left\{A_{\exp }\left(\Omega_{i}\right)\right.$ $\left.-A_{\text {fit }}\left(\Omega_{i}\right)\right\}$ are observed for the regions of both maximums and minimums of the absorbance for both phenyl bands. This inaccuracy gives rise to a substantial (up to $50 \%$ and 100\%) overestimation of the dichroic ratio $R_{\text {(fit) }}$ calculated using the formulas $R_{\text {(fit) }}=A_{\max (\mathrm{fit})} / A_{\min (\mathrm{fit})}$ for the bands at 1603 and $1525 \mathrm{~cm}^{-1}$ for the applied voltage of $40 \mathrm{~V}$ in comparison with the exact values of $R_{1603}$ and $R_{1525}$ obtained after an accurate analysis of the extremes of the absorbance profiles. A relative inaccuracy in the determination of $A_{\min }$ is especially large. For $U_{\mathrm{DC}}=-40 \mathrm{~V}$, the observed deviations $\Delta A\left(\Omega_{i}\right)$ in the vicinity of the extremes are rather small.

For determining the exact values of $A_{\max }$ and $A_{\min }$ of the real phenyl absorbance profiles, the experimental data in the local angular regions of the extremes were additionally fitted using polynomial functions using the procedure described in [31]. A small angular step $\Delta \Omega=6^{\circ}$ in the polarizer rotation angle during the spectral measurements was used for obtaining exact values of $A_{\max }$ and $A_{\min }$ for the phenyl absorbance profiles. The accurately fitted $\Omega_{\max }, A_{\max }, A_{\min }$, and the respective calculated values of the dichroic ratio $R$ $=A_{\max } / A_{\min }$ for the studied bands are considered below.

\section{B. Voltage dependencies of the dichroic parameters}

The voltage dependencies of the dichroic parameters $\Omega_{\max 1603}, A_{\max 1603}, A_{\min 1603}$, and $R_{1603}$ for the intensive high-dichroic phenyl band at $1603 \mathrm{~cm}^{-1}$ are shown in Figs. $8-10$, respectively. Similar relative changes in the voltage dependencies of these parameters were also observed for the band at $1525 \mathrm{~cm}^{-1}$. Since normally for both these phenyl vibrations, the polar angles $\beta_{1603}$ and $\beta_{1525}$ are sufficiently small ( $\beta_{1603} \leqslant 20^{\circ}$ for the various compounds) the mean orientations of the respective transition moments $\mathbf{M}_{1603}$ and $\mathbf{M}_{1525}$ are approximately parallel to the molecular long axes even in the case of a small biasing in the molecular rotational orientational distributions. The direction and the degree of the preferable orientation of the molecular directors can be characterized by the parameters $\Omega_{\max }$ and $R$ for the most dichroic phenyl band. A lower estimation of the orientational order parameter $\left\langle P_{2}\right\rangle$ is calculated using the formulas $\left\langle P_{2}\right\rangle$ $=\left(R_{1525}-1\right) /\left(R_{1525}+2\right)$.

For temperatures of 122,121 , and $120.5^{\circ} \mathrm{C}$, which correspond to the $\mathrm{Sm} A^{*}$ phase of the compound in the absence of the external field, an application of the dc bias voltage across the cell induces characteristic changes in the dichroic parameters of the various bands [see Figs. 6(a) and 8-10]. For zero field, the maximal intensities of both phenyl bands are observed in the IR radiation polarization direction parallel to the smectic layer normal. This corresponds to $\Omega_{\max 1603} \approx \Omega_{\max 1525} \approx 0^{\circ}$ after a subtraction $\Omega_{\max v}=\Omega_{C_{\max v}}$ $-\vartheta$. The applied voltages of opposite polarities $\left( \pm U_{\mathrm{DC}}\right)$ induce the angular shifts of the absorbance profile for a band by the same absolute value (specific for a certain band) but in the opposite directions $\left( \pm \Delta \Omega_{\max v}\right)$ [see Fig. 6(a)]. The plots in Figs. 8-10 for a fixed temperature can be divided into three characteristic regions. (i) For comparatively low voltages from zero to a temperature-dependent threshold voltage 
TABLE II. The dichroic parameters $\Omega_{\max \nu}$ and $R_{\nu}$ for the bands at 1525,1603 , and $1715 \mathrm{~cm}^{-1}$ and the order parameter $\left\langle P_{2}\right\rangle[$ lower estimation using $R_{1525}\left(U_{1}\right)$ ] for a $6 \mu \mathrm{m}$ cell of MHPHFHHOBC at several temperatures for zero and for sufficiently high voltages $\left(U_{1}\right)$ inducing the unwound ferroelectric structure.

\begin{tabular}{|c|c|c|c|c|c|c|c|}
\hline $\begin{array}{l}T \\
\left({ }^{\circ} \mathrm{C}\right)\end{array}$ & $\begin{array}{l}\text { Phase for } \\
\text { zero field }\end{array}$ & $\begin{array}{l}\text { Band } \\
\left(\mathrm{cm}^{-1}\right)\end{array}$ & $\begin{array}{c}\Omega_{\max \nu}(0) \\
\quad(\operatorname{deg})\end{array}$ & $\begin{array}{l}\Omega_{\max \nu}\left(U_{1}\right) \\
\quad(\operatorname{deg})\end{array}$ & $R_{\nu}\left(U_{1}\right)$ & $\left\langle P_{2}\right\rangle\left(U_{1}\right)$ & $\begin{array}{l}U_{1} \\
(\mathrm{~V})\end{array}$ \\
\hline \multirow[t]{3}{*}{122} & \multirow[t]{3}{*}{$\mathrm{SmA}^{*}$} & 1525 & 0 & 27.3 & 7.51 & \multirow[t]{3}{*}{0.685} & \multirow[t]{3}{*}{160} \\
\hline & & 1603 & 0 & 28.2 & 5.69 & & \\
\hline & & 1715 & 91.3 & 100.7 & 1.94 & & \\
\hline \multirow[t]{3}{*}{118} & \multirow[t]{3}{*}{$\mathrm{SmC}^{*}$} & 1525 & -29.5 & 33.6 & 9.11 & \multirow[t]{3}{*}{0.73} & \multirow[t]{3}{*}{40} \\
\hline & & 1603 & -30.8 & 34.6 & 7.09 & & \\
\hline & & 1715 & 79.5 & 104.8 & 2.03 & & \\
\hline \multirow[t]{3}{*}{65} & \multirow[t]{3}{*}{$\mathrm{SmC}_{\mathrm{A}}^{*}$} & 1525 & -3.6 & 43.4 & 13.43 & \multirow[t]{3}{*}{0.806} & \multirow[t]{3}{*}{40} \\
\hline & & 1603 & -3.5 & 44.1 & 10.18 & & \\
\hline & & 1715 & 89.8 & 105.2 & 2.82 & & \\
\hline
\end{tabular}

$\left(U_{\text {thr }}\right)$, the angle $\Omega_{\max } 1603$ rises slowly and almost linearly with increasing voltage (Fig. 8). $U_{\text {thr }}$ is equal to $\sim 100 \mathrm{~V}$, $\sim 40 \mathrm{~V}$, and $\sim 30 \mathrm{~V}$ for temperatures of 122,121 , and $120.5{ }^{\circ} \mathrm{C}$, respectively. The derivative $d \Omega_{\max 1603} / d U_{\mathrm{DC}}$ also exhibits a weak dependence on the temperature and lies in the range from $0.12\left({ }^{\circ} / \mathrm{V}\right)$ at $122{ }^{\circ} \mathrm{C}$ to $0.17(\% / \mathrm{V})$ at $120.5{ }^{\circ} \mathrm{C}$. The parameters $A_{\max 1603}, A_{\min 1603}, R_{1603}$ and the
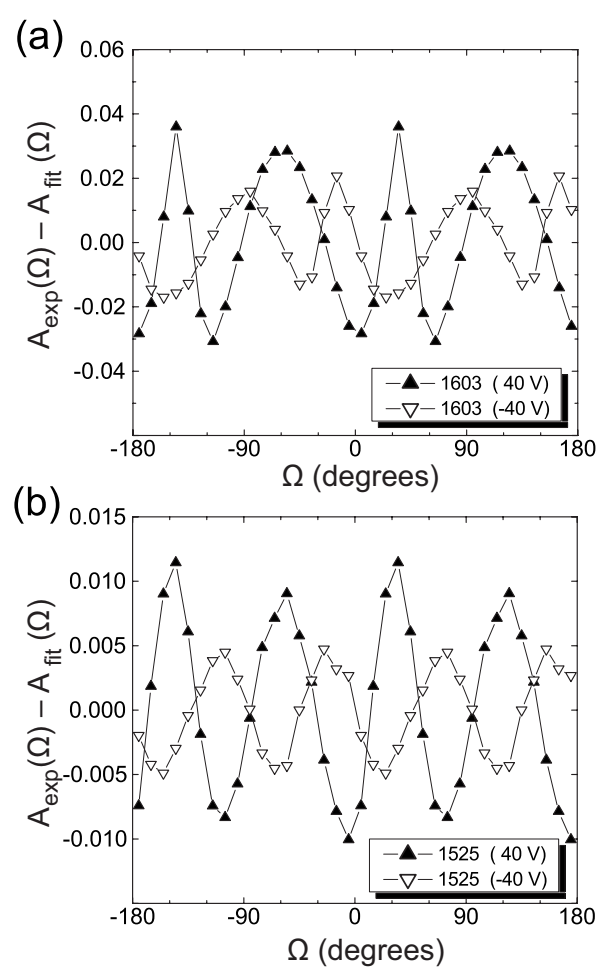

FIG. 7. The deviations $\left\{A_{\text {exp }}\left(\Omega_{i}\right)-A_{f i t}\left(\Omega_{i}\right)\right\}$ of the experimental data, $A_{\text {exp }}\left(\Omega_{i}\right)$, for the polarization angles $\Omega_{i}$ from the points $A_{f i t}\left(\Omega_{i}\right)$ of the fitting curve function (5) vs the polarization angle $\Omega$ for the bands at $1603 \mathrm{~cm}^{-1}$ (a) and $1525 \mathrm{~cm}^{-1}$ (b). The illustration corresponds to a typical data for the 6 ( $\mathrm{m}$ cell of MHРHFHНОВC at $118^{\circ} \mathrm{C}$. order parameter $\left\langle P_{2}\right\rangle$ remain almost constant for this voltage interval. This corresponds to a significantly large electroclinic effect in $\operatorname{Sm} A^{*}$ [31].

(ii) For the second voltage range from $U_{\text {thr }}$ to a saturating voltage $\left(U_{\text {sat }}\right)$, the parameters $\Omega_{\max 1603}$ and $R_{1603}$ (Fig. 8) show a rapid rise with increasing voltage and then lead to slow saturation for $U_{\mathrm{DC}} \approx U_{\text {sat }}$. Values of $U_{\text {sat }}$ are large enough and temperature dependent, varying from $\sim 140 \mathrm{~V}$ for $122{ }^{\circ} \mathrm{C}$ to $\sim 60 \mathrm{~V}$ for $120.5^{\circ} \mathrm{C}$. It is interesting to note that $d \Omega_{\max 1603} / d U_{\mathrm{DC}}$ for $U_{\mathrm{thr}}<U_{\mathrm{DC}}<U_{\text {sat }}$ is approximately 3-5 times larger than for $U_{\mathrm{DC}}<U_{\mathrm{thr}}$. The absorbances $A_{\max } 1603$ and $A_{\min 1603}$ demonstrate opposite tendencies:

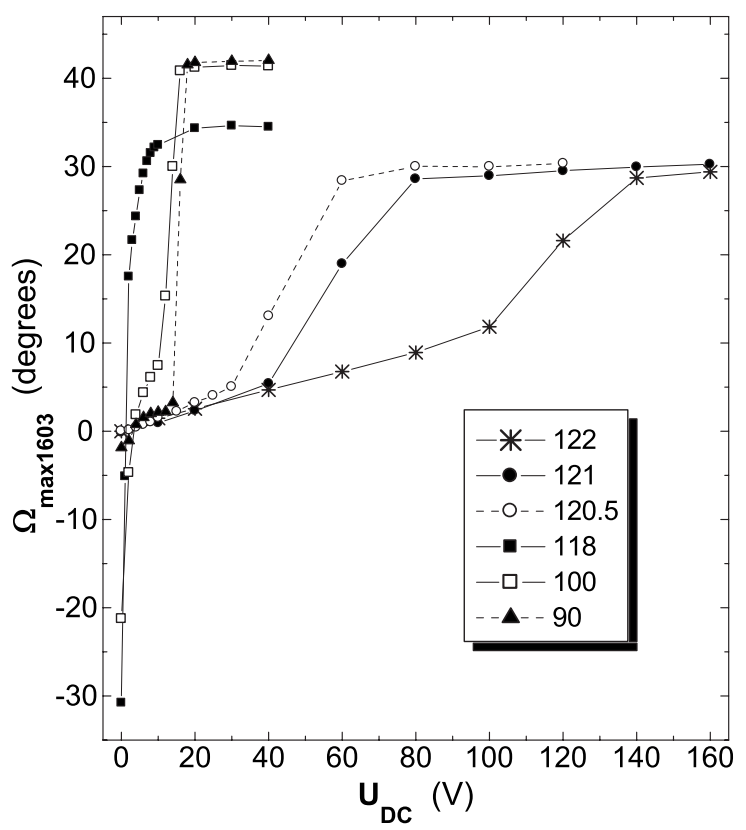

FIG. 8. The voltage dependences of the polarization angle $\Omega_{\max 1603}$ for the phenyl band at $1603 \mathrm{~cm}^{-1}$ in a homogeneously aligned cell of $6 \mu \mathrm{m}$ thickness at several temperatures. Lines interconnect adjacent experimental points (illustration of curves and temperatures in ${ }^{\circ} \mathrm{C}$ are shown in the inset). 

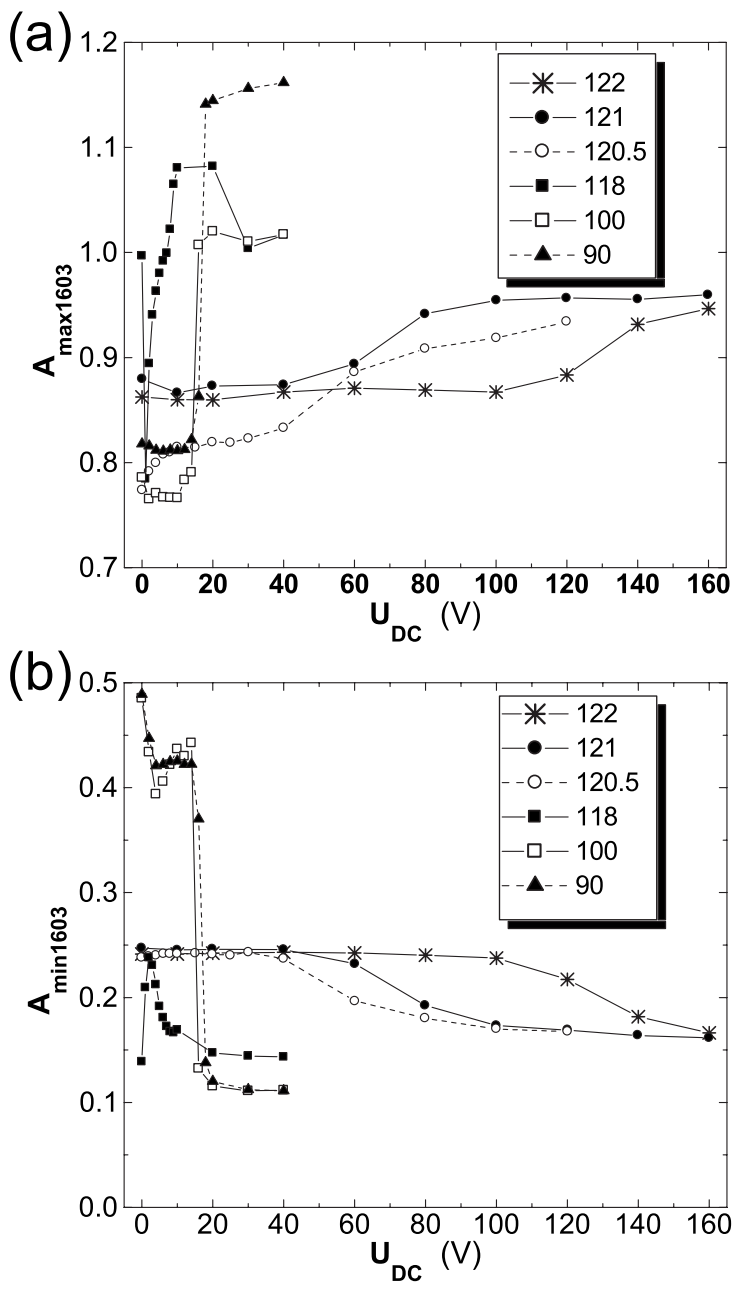

FIG. 9. The voltage dependences of the absorbance parameters $A_{\max 1603}$ (a) and $A_{\min 1603}$ (b) for the phenyl band at $1603 \mathrm{~cm}^{-1}$ in a homogeneously aligned cell of $6 \mu \mathrm{m}$ thickness for several temperatures. Lines interconnect adjacent experimental points (illustration of curves and temperatures in ${ }^{\circ} \mathrm{C}$ shown in the inset).

$A_{\max } 1603$ rises but $A_{\min 1603}$ decreases with increasing voltage (Fig. 9). This results in a considerable increase in the dichroic ratio $R_{1603}$ (Fig. 10) and the order parameter $\left\langle P_{2}\right\rangle$, which is increased from $\sim 0.455$ for $U_{\mathrm{DC}}=40 \mathrm{~V}$ to $\sim 0.625$ for $U_{\mathrm{DC}}=160 \mathrm{~V}$. Such a dichroic behavior does also correspond to a significantly large electroclinic effect.

(iii) For the third voltage range $\left(U_{\mathrm{DC}}>U_{\text {sat }}\right), \Omega_{\max 1603}$, $R_{1603}$, and $\left\langle P_{2}\right\rangle$ are slowly increasing with voltage (see Fig. $8)$. The derivative $d \Omega_{\max 1603} / d U_{\mathrm{DC}}$ is about 4-5 times lower than that for the low-voltage interval $\left(U_{\mathrm{DC}}<U_{\mathrm{thr}}\right)$. For applied voltages $U_{\mathrm{DC}}>U_{\text {sat }}$, the field-induced state of the sample is ferroelectric with the molecular directors orientated parallel to the cell substrates.

Such a behavior of the dichroic parameters of the phenyl band and the orientational order parameter $\left\langle P_{2}\right\rangle$ for the temperature range $120.5-122{ }^{\circ} \mathrm{C}$ under electric fields as reported above is extremely interesting. The results show a significantly large electroclinic effect corresponding to the phase transition from tilted $\operatorname{Sm} A^{*}$ to the electric-fieldinduced synclinic $\mathrm{SmC}^{*}$. This property is also typical of the

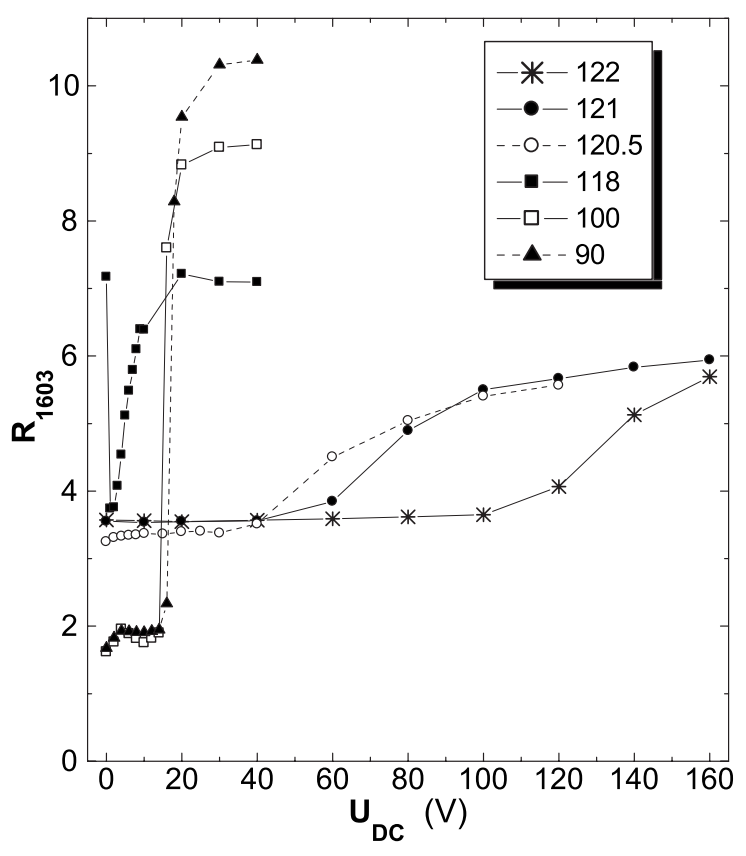

FIG. 10. The voltage dependences of the dichroic ratio $R_{1603}$ $=A_{\max } 1603 / A_{\min } 1603$ for the phenyl band at $1603 \mathrm{~cm}^{-1}$ in a homogeneously aligned cell of $6 \mu \mathrm{m}$ thickness at several temperatures. Lines interconnect adjacent experimental points (illustration of curves and temperatures in ${ }^{\circ} \mathrm{C}$ shown in the inset).

de Vries $\operatorname{Sm} A^{*}$ material [15], for which at zero external field the in-layer directors are tilted but azimuthally randomly distributed on a smectic cone through $\varphi$ (see Fig. 3) with an axial symmetry. The electric field induces an alignment of the molecular director azimuthal angles and this gives rise to a significantly large electroclinic effect. The material investigated has the tilted $\operatorname{Sm} A^{*}$ phase of de Vries type. This conclusion is supported also by experimental data on x-ray layer thickness given in Fig. 2, as already discussed.

For temperatures corresponding to the $\mathrm{SmC}^{*}$ phase $\left(118^{\circ} \mathrm{C}\right)$ and the metastable coexistence of $\mathrm{SmC}^{*}$ and $\mathrm{SmC}_{\mathrm{A}}{ }^{*}\left(100{ }^{\circ} \mathrm{C}\right)$ for low voltages $\left(U_{\mathrm{DC}}<2 \mathrm{~V}\right)$, a rather large finite apparent tilt angle is observed in terms of finite $\Omega_{\max 1603}$ (see Fig. 8 and Table II). Similar behavior of the apparent tilt angle was reported by Rudquist et al. for orthoconic compounds in a thin cell [9]. This effect is anticipated to arise from a partial disturbance of the helix, unwound domains, metastable synclinic state caused by the chevron structure, large relaxation time of the phase structural transformations and the molecular anchoring at the cell substrates surfaces. For $\mathrm{SmC}_{A}{ }^{*}$ at $90{ }^{\circ} \mathrm{C}$, a rather small $\Omega_{\max 1603}$ as well as $\Omega_{\max 1525}$ were observed for the sample at zero field (see Fig. 8 and Table II). A similar deviation of the apparent tilt angle at zero field observed for an orthoconic liquid crystal in $\mathrm{SmC}_{A}{ }^{*}$ was attributed to a so-called "apparent pretransition state" caused by the unwinding of the macroscopic helix by the surface interactions [9].

For $\mathrm{SmC}^{*}$ at $118^{\circ} \mathrm{C}$, a rapid increase in $\Omega_{\max 1603}$ and $R_{1603}$ is observed with voltage increasing from $1-8 \mathrm{~V}$. For $\mathrm{SmC}_{A}{ }^{*}$ at $90{ }^{\circ} \mathrm{C}$, a rapid increase in $\Omega_{\max 1603}$ and $R_{1603}$ with voltage is observed for voltages higher than a saturating volt- 


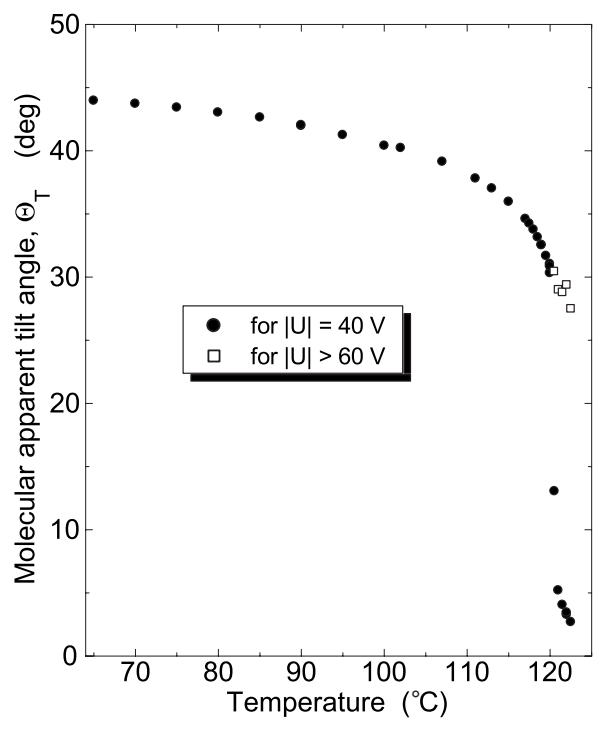

FIG. 11. The temperature dependence of the molecular apparent tilt angle $\Theta_{T}$ determined from the values of $\Omega_{\max 1603}$ for the applied voltages of $\pm 40 \mathrm{~V}$ for the entire temperature range studied (solid circles) and for the temperature dependent saturating voltages $\pm U_{\text {sat }}$ for the range $120.5-122.5^{\circ} \mathrm{C}$ (open squares). Explanation is provided in the text.

age of $\sim 15 \mathrm{~V}$. A saturation in the dichroic parameters for both these temperatures is reached for voltages $\sim 18-20 \mathrm{~V}$.

\section{Temperature dependence of the molecular apparent tilt angle}

The average molecular tilt angle $\Theta_{T}$ is determined from the saturated values of $\Omega_{\max 1525}$ (rather close to $\Omega_{\max 1603}$ ) for positive and negative applied voltages since the band at $1525 \mathrm{~cm}^{-1}$ exhibits the highest dichroism and the polar angle $\beta_{1525}$ is assumed to be close to zero. It is essential to take into account both field polarities since for the $\mathrm{SmC} C^{*}$ and $\mathrm{Sm}_{A}{ }^{*}$ temperature ranges, the value of $\Omega_{\max } 1525$ at zero field is not equal to zero and does not correspond to the orientation of the smectic layer normal (see the previous section).

Figure 11 shows the temperature dependence of the molecular apparent tilt angle of the compound. Solid circles represent $\Theta_{T( \pm 40)}$ obtained from the experimental data for the applied voltages of $40 \mathrm{~V}$ and $-40 \mathrm{~V}$ using the equation

$$
\begin{aligned}
\Theta_{T( \pm 40)}= & {\left[\Omega_{\max 1603}\left(U_{\mathrm{DC}}=40 \mathrm{~V}\right)\right.} \\
& \left.-\Omega_{\max 1603}\left(U_{\mathrm{DC}}=-40 \mathrm{~V}\right)\right] / 2 .
\end{aligned}
$$

For a temperature range of $65-120{ }^{\circ} \mathrm{C}$ corresponding to $\mathrm{SmC}_{A}{ }^{*}$ and $\mathrm{SmC}^{*}$ phases, the obtained values of $\Theta_{T( \pm 40)}$ characterize the average molecular tilt angle reasonably because these voltages are higher than required to reach saturation in $\Omega_{\max 1525}$ with field (see Fig. 8). For a temperature range of $65-80{ }^{\circ} \mathrm{C}, \Theta_{T}$ lies in the range $43^{\circ}-44^{\circ}$, with a smectic tilt cone angle of $86^{\circ}-88^{\circ}$ and hence the anticlinic $\mathrm{SmC}_{A}{ }^{*}$ structure is only slightly short of being completely orthoconic.
For a temperature range of $120.5-122.5^{\circ} \mathrm{C}$ that corresponds to $\mathrm{Sm} A^{*}$ phase, the voltages of $\pm 40 \mathrm{~V}$ are not large enough to induce $\mathrm{Sm}^{*}$ with an unwound structure, since saturated values $\Omega_{\max 1603} \approx 30^{\circ}$ and $R_{1603} \approx 6$ are observed for considerably higher voltages (see Figs. 8 and 10). For this temperature range, the values of $\Theta_{T( \pm 40)}$ lie in the range $2^{\circ}-15^{\circ}$ (solid circles in Fig. 10), are considerably less that the saturated values at $V \geqslant 150 \mathrm{~V}$, and hence represent only some intermediate apparent tilt angles for given applied voltages. In order to find reasonable values of the tilt angle, the measurements are made in the induced unwound $\mathrm{Sm} C^{*}$ phase. As seen from Fig. 8, for a temperature range of $120.5-122.5^{\circ} \mathrm{C}$, the saturating voltage $U_{\text {sat }}$ varies in the range from $60 \mathrm{~V}$ (for $120.5^{\circ} \mathrm{C}$ ) to $160 \mathrm{~V}$ (for $122.5^{\circ} \mathrm{C}$ ). The saturated values of the molecular apparent tilt angle for this temperature range were calculated using the equation $\Theta_{T}=\left[\Omega_{\max 1525}\left(U_{\text {sat }}\right)-\Omega_{\max 1525}\left(-U_{\text {sat }}\right)\right] / 2$. Thus obtained values of $\Theta_{T}$ lie in the range $28^{\circ}-31^{\circ}$ and are represented by open squares in Fig. 11.

The voltage dependence of the tilt angle $\Theta_{T}$ is shown in Fig. 11 in two steps: solid circles for a temperature range of $65-120^{\circ} \mathrm{C}$ and open squares for $120.5-122.5^{\circ} \mathrm{C}$. It would appear that the behavior of the $\mathrm{Sm} A^{*}$ phase exhibiting such a large tilt angle is rather unusual and appears to show some characteristics of de Vries $\operatorname{Sm} A^{*}$ in a temperature range of $120.5-122.5^{\circ} \mathrm{C}$.

\section{Polar angles and the rotational biasing for the vibrational transition moments}

The dichroic properties of the sample with the fieldinduced unwound $\mathrm{SmC}^{*}$ structures show the existence of large biasing in the rotational orientational distribution of molecules with respect to their long axes. This conclusion follows from a comparison of the observed polarization angles $\Omega_{\max }$ for the phenyl and the carbonyl bands. For $\mathrm{Sm} A^{*}$ at $122{ }^{\circ} \mathrm{C}$ and zero voltage, we have $\Omega_{\max 1525}$ $=\Omega_{\max 1603}=0^{\circ}$ (the polarization direction is along the smectic layer normal) and $\Omega_{\max 1715} \approx 90^{\circ}$ [see Table II and Figs. 6(a) and 8]. For this case, the long axis of the absorbance profile for the carbonyl band is perpendicular to the long axes of the absorbance profiles for both phenyl bands. However for the sample with the field-induced unwound ferroelectric structures, the polarization directions to the maximal absorbance of the carbonyl bands turn to be nonperpendicular to those of the phenyl bands for all studied temperatures. For example, for temperatures 122,118 , and $65^{\circ} \mathrm{C}$, the differences $\left[\Omega_{\max 1715}\left(U_{1}\right)-\Omega_{\max 1525}\left(U_{1}\right)\right]$ are equal to $73.4^{\circ}$, $71.2^{\circ}$, and $61.8^{\circ}$, respectively (see Table II). According to the analysis [23], the asymmetry of the absorbance profile of the carbonyl band with respect to the main axes of the phenyl band absorbance profile is the result of rotational biasing for the molecules in the tilted smectic phase. The rotational orientation of molecules is characterized by the function $f(\gamma)$ which shows the distribution of the vibrational transition moment of an absorption band through an azimuthal angle $\gamma$ measured with respect to the normal to the molecular tilt plane $\left(X_{\mathrm{T}}\right.$ axis in Fig. 4). For an unwound structure, $X_{\mathrm{T}}$ axis is normal to the substrates. The observed large deviation (by 
TABLE III. The mean parameters $\left\langle\cos ^{2} \Theta\right\rangle$ and $\langle\sin \Theta \cos \Theta\rangle$ for the molecular directors; the polar angles $\beta_{\nu}$ and the mean azimuthal parameter $\langle\sin \gamma\rangle$ for the transition moments for the bands at 1603 and $1715 \mathrm{~cm}^{-1}$ for several temperatures $(T)$ and sufficiently high voltages $\left(U_{1}\right)$. Sample: a $6 \mu \mathrm{m}$ cell of MHPHFHHOBC with the unwound ferroelectric structure.

\begin{tabular}{lcccccc}
\hline \hline $\begin{array}{l}T \\
\left({ }^{\circ} \mathrm{C}\right)\end{array}$ & $U_{1}$ & $\left\langle\cos ^{2} \Theta\right\rangle$ & $\langle\sin \Theta \cos \Theta\rangle$ & $\begin{array}{c}\text { Band } \\
\left(\mathrm{cm}^{-1}\right)\end{array}$ & $\begin{array}{c}\beta_{\nu} \\
(\mathrm{deg})\end{array}$ & $\langle\sin \gamma\rangle$ \\
\hline 122 & 160 & 0.722 & -0.312 & 1525 & 0 & - \\
& & & 1603 & 16.5 & -0.067 \\
& & & 1715 & 63.9 & -0.172 \\
118 & 40 & 0.656 & -0.37 & 1525 & 0 & - \\
& & & 1603 & 14.2 & -0.066 \\
& & & 1715 & 63.5 & -0.194 \\
& \multirow{2}{*}{40} & 0.524 & -0.43 & 1525 & 0 & - \\
& & & 1603 & 12.4 & -0.058 \\
& & & 1715 & 62.8 & -0.342 \\
\hline \hline
\end{tabular}

$\left.17^{\circ}-28^{\circ}\right)$ of the angular differences $\left[\Omega_{\max 1715}\left(U_{1}\right)\right.$ $\left.-\Omega_{\max 1525}\left(U_{1}\right)\right]$ from $90^{\circ}$ confirms the existence of a large biasing in the molecular distribution function $f(\gamma)$ for the unwound $\mathrm{SmC}^{*}$ structures of the compound.

The experimental dichroic data for the bands at 1525 , 1603 , and $1715 \mathrm{~cm}^{-1}$ for the field-induced unwound $\mathrm{Sm} C^{*}$ structures is analyzed to determine the polar angles $\beta$ for the phenyl and carbonyl transition moments and to estimate the degree of biasing in the molecular azimuthal distribution through $\gamma$ using the procedure given in [29]. For each of these three bands we consider two equations for the dichroic ratios (6) and (7) for temperatures 122,118 , and $65^{\circ} \mathrm{C}$. The angular functions (2)-(4) for the unwound $\mathrm{Sm} C^{*}$ structure are combined with the numerical values (8) and (9) obtained using the adjusted parameters listed in Table II. The azimutal distribution of the transition moments through the angle $\gamma$ is approximated by the function $f(\gamma)$ with one Fourier component [22],

$$
f(\gamma)=(2 \pi)^{-1}+a_{1} \cos \left(\gamma-\gamma_{0_{\nu}}\right)
$$

with the biasing coefficient $a_{1}$ (for definiteness, $a_{1} \geqslant 0$ ) and the biasing angle $\gamma_{0_{v}}$ for a certain band. It may be remarked that this distribution function was first introduced by Kim et al. [22] and later modified by Jang et al. [23] who introduced a coefficient $\left|a_{2}\right| \geqslant 0$ for the quadrupolar order. Later detailed studies by Sigarev et al. [31] on a deuterated chiral compound has shown that $\left|a_{2}\right| \ll a_{1}$ by at least a factor of 20 , less than $4 \%$ which lies within the experimental uncertainty. This leads us to the conclusion that $\left|a_{2}\right| \approx 0$. This apparent puzzle is resolved by surmising that the quadrupolar order arising from the head and tail equivalence of the molecule gives rise to a symmetrical disposition of the transition moments of the carbonyl group and is therefore not reflected in the IR measurements. Whether the mixing of $R$ and $S$ enantiomer will yield a finite value of $\left|a_{2}\right|$ is not yet known. The polarized IR therefore seem to yield only the polar order. For this function, the parameters $\langle\sin \gamma\rangle$ and $\left\langle\sin ^{2} \gamma\right\rangle$ used in Eqs. (2)-(4) are as follows:

$$
\begin{gathered}
\left\langle\sin \gamma_{\nu}\right\rangle=a_{1} \pi \sin \gamma_{0_{\nu}}, \\
\left\langle\sin ^{2} \gamma_{\nu}\right\rangle=0.5 .
\end{gathered}
$$

The unknown parameters $\left\langle\cos ^{2} \Theta\right\rangle$, $\langle\sin \Theta \cos \Theta\rangle$ for the directors and $\beta_{\nu}$ and $\left\langle\sin \gamma_{\nu}\right\rangle$ for each band are determined by solving a system of Eqs. (6) and (7) for the bands for a fixed temperature using program MATHCAD 2000 PRO. For the most dichroic band at $1525 \mathrm{~cm}^{-1}$, we use $\beta_{1525}=0^{\circ}$ as a first approximation. For the bands at 1603 and $1715 \mathrm{~cm}^{-1}$, the initial values were taken varying in the ranges of $0^{\circ}$ to $20^{\circ}$ and $60^{\circ}$ to $70^{\circ}$, respectively, in accordance with the molecular structure analysis. The parameters $\left\langle\cos ^{2} \Theta\right\rangle,\langle\sin \Theta \cos \Theta\rangle$, $\beta_{1603}, \beta_{1715}$, $\left\langle\sin \gamma_{1603}\right\rangle$ and $\left\langle\sin \gamma_{1715}\right\rangle$ determined for the approximation $\beta_{1525}=0^{\circ}$ are given in Table III. It is important to note that the observed difference in the values of the dichroic ratios $R_{1525}$ and $R_{1603}$ (Table II) corresponds to rather large values of $\beta_{1603}$ in the range from $12.4^{\circ}$ for a temperature of $65^{\circ} \mathrm{C}$ to $16.5^{\circ}$ for a temperature of $122{ }^{\circ} \mathrm{C}$. The values of $\beta_{1715}$ are found to lie in a comparatively narrow range within $1^{\circ}$ for various temperatures. Additional estimations using higher values of $\beta_{1525}$ (up to $10^{\circ}$ ) show a comparable increase in the obtained values of $\beta_{1603}$ and rather small changes in $\beta_{1715}$.

It is interesting to compare the determined parameter $\left\langle\cos ^{2} \Theta\right\rangle$ (see Table III) with the functions $\cos ^{2} \Omega_{\max 1525}$ for the fitted $\Omega_{\max 1525}$ used in the calculations. The parameter $\left\langle\cos ^{2} \Theta\right\rangle$ is related not only to the in-layer tilting of molecules for $\mathrm{SmC}^{*}$ but also to the distribution of the molecular long axes through $\Theta$ due to the thermal fluctuations in the tilt plane (the soft mode). $\Omega_{\max 1525}$ corresponds to the preferable orientation of the respective transition moments, that are dependent not only on the molecular distribution through $\Theta$, but also on their angles $\beta_{\nu}$ and on the distribution through $\gamma$. The analysis shows that the calculated values of $\left\langle\cos ^{2} \Theta\right\rangle$ are less than $\cos ^{2} \Omega_{\max 1525}$ by approximately $9 \%, 5.5 \%$, and $0.7 \%$ for temperatures of 122,118 , and $65^{\circ} \mathrm{C}$, respectively. These differences reflect the relative intensity of the soft mode fluctuations which increase with temperature. The non- 


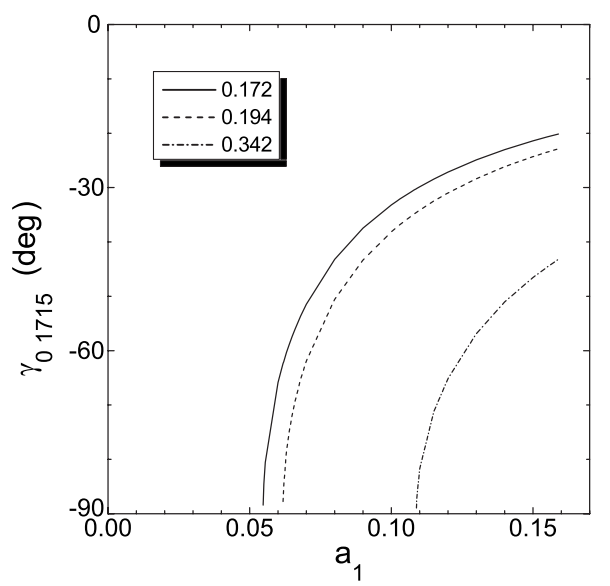

FIG. 12. Possible solutions of Eq. (12) for $\left\langle\sin \gamma_{1715}\right\rangle$ of -0.172 (curve 1), -0.194 (curve 2), and -0.342 (curve 3) determined for temperatures of 122,118 , and $65^{\circ} \mathrm{C}$, respectively.

linearity of the function $\left\langle\cos ^{2} \Theta\right\rangle$ should also be taken into account. For example, if to determine some "abstract tilt angle" $\Theta *$ from the equation $\cos ^{2} \Theta *=\left\langle\cos ^{2} \Theta\right\rangle$, the obtained values of $\Theta^{*}$ are equal to $31.8^{\circ}, 35.9^{\circ}$, and $43.6^{\circ}$ for temperatures 122,118 , and $65^{\circ} \mathrm{C}$, respectively. These angles are higher by $4.5^{\circ}, 2.3^{\circ}$, and $0.2^{\circ}$ in absolute term (and $\sim 17 \%$, $7 \%$, and $0.5 \%$ relatively) than the values of $\Omega_{\max 1525}$ obtained from experimental data for 122,118 , and $65^{\circ} \mathrm{C}$, respectively (see Table II). For a temperature range of $\mathrm{Sm} A^{*}$, the difference $\left(\Theta^{*}-\Omega_{\max 1525}\right)$ is rather large, whereas for the low-temperature range of $\mathrm{SmC}_{A}$ *, it is negligible. The results given by IR spectroscopy confirm the previously known fact that the magnitude of the tilt angle fluctuations are considerably enhanced close to the $\operatorname{Sm} A^{*}-\mathrm{Sm} C^{*}$ transition temperature. Note that a finite nonzero polar angle $\beta_{1525}$ may complicate the calculations significantly.

The calculated $\left|\left\langle\sin \gamma_{1715}\right\rangle\right|$ for the unwound $\mathrm{SmC}^{*}$ structures of the compound are equal to $-0.172,-0.194$, and -0.342 for temperatures 122,118 , and $65^{\circ} \mathrm{C}$, respectively (see Table III). In absolute terms these values are higher by a factor of 10 in comparison with those found for other usual AFLC compounds $[29,32]$ investigated. This is a direct evidence for the existence of considerable biasing in the rotational orientational distribution of the carbonyl groups with respect to the molecular long axes in the orthoconic compound. For the compound studied here, it is possible to analyze biasing in the distribution function $f(\gamma)$ using only one carbonyl band at $1715 \mathrm{~cm}^{-1}$ since the second carbonyl band at $1741 \mathrm{~cm}^{-1}$ is a complicated superposition of the two overlapping bands with different transition moments. Since each phenyl band is related to the two transition moments corresponding to the phenyl and biphenyl fragments of a molecule, it is difficult to determine relative values of the azimuthal angles $\gamma_{0_{\nu}}$ for the bands. Figure 12 shows possible regions of solutions of Eq. (12) for the parameters $\gamma_{0_{1715}}$ and $a_{1}$ for the determined values of $\left\langle\sin \gamma_{1715}\right\rangle$ for three temperatures. The azimuthal parameters of the phenyl band at $1603 \mathrm{~cm}^{-1}$ are omitted from the consideration in this step. The possible values of $a_{1}$ lie in the range $\pi^{-1}\left|\left\langle\sin \gamma_{1715}\right\rangle\right|$ $<a_{1} \leqslant(2 \pi)^{-1}$, since $\left|\sin \gamma_{0_{1715}}\right| \leqslant 1$ for Eq. (12) and $f(\gamma)$ $\geqslant 0$ for Eq. (11). For the field unwound $\mathrm{SmC}^{*}$ structures of the compound at 122,118 , and $65^{\circ} \mathrm{C}$, the biasing coefficient $a_{1}$ is comparatively high and varies in the ranges 0.055 to $0.159,0.062$ to 0.159 , and 0.109 to 0.159 , respectively.

\section{CONCLUSIONS}

The IR dichroic properties of a homogeneously aligned sample of a partly fluorinated chiral smectic liquid crystalline orthoconic compound MHPHFHHOBC lead us to draw the following conclusions on its molecular orientational behavior. A deviation of the layer normal by a finite angle of $\sim 12^{\circ}$ with respect to the rubbing direction in a homogeneously aligned LC cell and the observed substantial distortion of the helical structures for the $\mathrm{SmC}^{*}$ and $\mathrm{SmC}_{A}$ * phases at zero field across the cell are related to an anomalous large surface electroclinic effect exhibited by this material. For a temperature range of $120.5-122.5^{\circ} \mathrm{C}$ corresponding to $\mathrm{Sm} A^{*}$ phase, the material demonstrates a significantly large electroclinic effect, and a considerable increase in the orientational order parameter with the field is observed. An average molecular apparent tilt angle $\left(\sim 30^{\circ}\right)$ for sufficiently high electric fields is a result of the large electroclinic effect leading from $\mathrm{Sm} A^{*}$ to $\mathrm{Sm} C^{*}$ field-induced state. Such a behavior is also typical of the de Vries $\operatorname{Sm} A^{*}$ materials where for zero field there is a random azimuthal distribution of the molecular directors that are tilted within a narrow distribution of the tilt angle; though the data on layer shrinkage at the $\operatorname{Sm} A^{*}$ to $\mathrm{SmC} C^{*}$ transition shows only a partial de Vries character of $\operatorname{Sm} A^{*}$. For a temperature range $65-80^{\circ} \mathrm{C}$, the molecular apparent tilt angle is found to lie in the range $43^{\circ}-44^{\circ}$, consequently the anticlinic $\operatorname{Sm}_{A^{*}}$ phase exhibits an orthoconic structure short of at the most $2^{\circ}$ in the tilt angle. The tilt angle in $\mathrm{SmC}_{A}^{*}$ has been determined by applying electric field across the cell. The observed differences in the shapes of the experimental absorbance profile for the high-dichroic phenyl bands measured for the opposite polarities of the saturating electric fields are presumably related to a possible nonhomogeneity of the layer structure in the vicinity of the substrates and enhanced molecular surface interactions for this material. For the temperature ranges corresponding to $\mathrm{Sm}_{A}^{*}, \mathrm{Sm} C^{*}$, and de Vries $\mathrm{Sm} A^{*}$ phases, the field-induced unwound synclinic structures exhibit significantly large rotational orientational biasing of the carbonyl groups with respect to the molecular long axes, larger by a factor of $\sim 10$ compared to other materials studied so far. This is consistent with the observed large spontaneous polarization of the material studied $\sim 180 \mathrm{nC} / \mathrm{cm}^{2}$ and other materials reported in the literature [43]. This may also imply that the biasing does play an important role in giving rise to a large tilt angle in an orthoconic compound.

\section{ACKNOWLEDGMENTS}

The authors thank Atsuo Fukuda and V. P. Panov for fruitful discussions. The work was supported by the SFI (Contract No. 02/In.1/I031). 
[1] K. D'have, A. Dahlgren, P. Rudquist, J. P. F. Lagerwall, G. Andersson, M. Matuszcyk, S. T. Lagerwall, R. Dabrowski, and W. Drzewinski, Ferroelectrics 244, 415 (2000).

[2] K. D’have, P. Rudquist, S. T. Lagerwall, H. Pauwels, W. Drzewinski, and R. Dabrowski, Appl. Phys. Lett. 76, 3528 (2000).

[3] S. T. Lagerwall, A. Dahlgren, P. Jägemalm, P. Rudquist, K. D'Have, H. Pauwels, R. Dabrowski, and W. Drzewinski, Adv. Funct. Mater. 11, 87 (2001).

[4] G. Scalia, P. Rudquist, D. S. Hermann, K. D'have, S. T. Lagerwall, and J. R. Sambles, J. Appl. Phys. 91, 9667 (2002).

[5] J. P. F. Lagerwall, A. Saipa, F. Giesselmann, and R. Dabrowski, Liq. Cryst. 31, 1175 (2004).

[6] D. Elfström, P. Rudquist, J. Bengtsson, K. D'have, and S. Galt, Opt. Lett. 31, 3158 (2006).

[7] G. Galli, M. Ragnoli, E. Chellini, L. Komitov, and G. Andersson, Ferroelectrics 276, 37 (2006).

[8] P. Rudquist, D. Elfström, S. T. Lagerwall, and R. Dabrowski, Ferroelectrics 344, 177 (2006).

[9] C. D. Jones, U. C. Dawin, F. Giesselmann, P. Rudquist, and N. A. Clark, in Book of Abstracts of the 21st International Liquid Crystal Conference, Keystone, Colorado, 2006 (unpublished) Abstract FERRP-2, p. 586.

[10] M. J. O'Callaghan, M. Wand, C. Walker, W. Thurmes, and K. More, Ferroelectrics 343, 201 (2006).

[11] H. F. Gleeson, Y. Wang, S. Watson, D. Sahagum-Sanchez, J. W. Goodby, M. Hird, A. Petrenko, and M. A. Osipov, J. Mater. Chem. 14, 1480 (2004).

[12] W. K. Robinson, P. S. Kloess, C. Carboni, and H. J. Coles, Liq. Cryst. 23, 309 (1997).

[13] W. K. Robinson, C. Carboni, P. S. Kloess, S. P. Perkins, and H. J. Coles, Liq. Cryst. 25, 301 (1998).

[14] N. Olsson, I. Dahl, B. Helgee, and L. Komitov, Liq. Cryst. 31, 1555 (2004).

[15] O. E. Panarina, Yu. P. Panarin, J. K. Vij, M. S. Spector, and R. Shashidhar, Phys. Rev. E 67, 051709 (2003).

[16] O. E. Panarina, Yu. P. Panarin, F. Antonelli, J. K. Vij, M. Reihmann, and G. Galli, J. Mater. Chem. 16, 842 (2006).

[17] O. E. Kalinovskaya, Yu. P. Panarin, and J. K. Vij, Europhys. Lett. 57(2), 184 (2002).

[18] O. E. Panarina, Yu. P. Panarin, J. K. Vij, M. S. Spector, and R. Shashidhar, Phys. Rev. E 67, 051709 (2003).

[19] N. Kirov and P. Simova, Vibrational Spectroscopy of Liquid Crystals (Bulgarian Academy of Sciences, Sofia, 1984).

[20] M. Zgonik, M. Rey-Lafon, C. Destrade, C. Leon, and H. T. Nguyen, J. Phys. (France) 51, 2015 (1990).

[21] E. Hild, A. Kocot, J. K. Vij, and R. Zentel, Liq. Cryst. 16, 783 (1994).

[22] K. H. Kim, K. Ishikawa, H. Takezoe, and A. Fukuda, Phys. Rev. E 51, 2166 (1995).

[23] W. G. Jang, C. S. Park, J. E. Maclennan, K. H. Kim, and N. A.
Clark, Ferroelectrics 180, 213 (1996).

[24] Bo Jin, Z. Ling, Y. Takanishi, K. Ishikawa, H. Takezoe, A. Fukuda, M. A. Kakimoto, and T. Kitazume, Phys. Rev. E 53, R4295 (1996).

[25] A. Kocot, R. Wrzalik, B. Orgasinska, T. S. Perova, J. K. Vij, and H. T. Nguyen, Phys. Rev. E 59, 551 (1999).

[26] A. Kocot, J. K. Vij, and T. S. Perova, in Advances in Liquid Crystals, edited by J. K. Vij, Adv. Chem. Phys. 113, 203 (2000).

[27] A. A. Sigarev, J. K. Vij, Yu. P. Panarin, and J. W. Goodby, Phys. Rev. E 62, 2269 (2000).

[28] A. A. Sigarev, J. K. Vij, Yu. P. Panarin, P. Rudquist, S. T. Lagerwall, and G. Heppke, Liq. Cryst. 30, 149 (2003).

[29] A. A. Sigarev, J. K. Vij, R. A. Lewis, M. Hird, and J. W. Goodby, Phys. Rev. E 68, 031707 (2003).

[30] J. P. F. Lagerwall and F. Giesselmann, ChemPhysChem 7, 20 (2006).

[31] A. A. Sigarev, J. K. Vij, A. Fukuda, Bo Jin, and Y. Takanishi, Ferroelectrics 311, 97 (2004).

[32] L. M. Sverdlov, M. A. Kovner, and E. P. Krainov, Vibrational Spectra of Polyatomic Molecules (Israel Program of Science Translations, Jerusalem, 1974).

[33] K. Tashiro, J. Hou, M. Kobayashi, and T. Inoue, J. Am. Chem. Soc. 112, 8273 (1990).

[34] R. Zbinden, Infrared Spectroscopy of High Polymers (Academic, New York, 1964).

[35] K. Abe and K. Yanagisawa, J. Polym. Sci. 36, 536 (1959).

[36] B. K. P. Scaife and J. K. Vij, J. Chem. Phys. 122, 174901 (2005).

[37] K. Nakagawa, T. Shinomiya, M. Koden, T. Tsubota, T. Kuratate, Y. Ishii, F. Funada, M. Matsuura, and K. Awane, Ferroelectrics 85, 39 (1988).

[38] J. Xue and N. A. Clark, Phys. Rev. Lett. 64, 307 (1990).

[39] W. Chen, Y. Ouchi, T. Moses, Y. R. Shen, and K. H. Yang, Phys. Rev. Lett. 68, 1547 (1992).

[40] P. Rudquist, K. D'have, M. Linehan, T. Gammelgard, S. T. Lagerwall, and W. Drzewinski, Book of Abstracts of the 9th International Liquid Crystal Conference, Dublin, Ireland 2003, edited by J. K. Vij (unpublished), oral presentation number 10 ..

[41] S. S. Seomun, V. P. Panov, and J. K. Vij, Ferroelectrics 278, 151 (2002).

[42] N. M. Shtykov, J. K. Vij, and M. I. Barnik, Mol. Mater. 11, 171 (1999).

[43] P. Rudquist, J. P. F. Lagerwall, M. Buivydas, F. Gouda, S. T. Lagerwall, N. A. Clark, J. E. Maclennan, R. Shao, D. A. Coleman, S. Bardon, T. Bellini, D. R. Link, G. Natale, M. A. Glaser, D. M. Walba, M. D. Wand, and X.-H. Chen, J. Mater. Chem. 9, 1257 (1999).

[44] L. J. Bellamy, The infrared spectra of complex molecules (Methuen, London, 1954). 